\title{
Eficácia do Gasto Público: Uma Avaliação do FNE, FNO e FCO
}

\author{
- Alexandre Manoel angelo da Silva * - Guilherme Mendes Resende** \\ - RaUl da MOta Silveira Neto***
}

\begin{abstract}
RESUMO
Este artigo avalia e compara a eficácia dos empréstimos dos recursos do Fundo Constitucional de Financiamento do Nordeste (FNE), do Fundo Constitucional de Financiamento do Norte (FNO) e do Fundo Constitucional de Financiamento do Centro-Oeste (FCO), no período 2000-2003, a partir das estimativas de propensity score das firmas beneficiadas com recursos desses fundos constitucionais e de um conjunto de firmas não-beneficiadas por esses fundos. Em relação ao FNE, o resultado geral diz respeito ao impacto positivo sobre a taxa de variação do número de empregados e à ausência de impacto sobre a taxa de variação do salário médio pago pelas firmas. No que concerne ao FNO e FCO, não é possível apontar qualquer tipo de impacto nas variáveis em análise.
\end{abstract}

\section{Palavras-Chave}

FNE, FNO, FCO, número de empregados e salário

\begin{abstract}
During the period 2000-2003, this paper evaluates and compares the efficacy of Financing Constitutional Fund of the Northeast (FNE), North (FNO) and Center- West (FCO) loans using propensity score estimates of firms that have received loans and of others that have not. In relation to FNE, the general result indicates a positive impact on the growth rate of employee number and no impact on the growth rate of wages paid for firms. In relation to FNO and FCO, there is not possible to indicate any kind of impact on the analyzed variables.
\end{abstract}

\section{KEYWORDS}

FNE, FNO, FCO, employee number and wage

JEL Classification

H53, H54

\footnotetext{
* Técnico de Planejamento e Pesquisa do IPEA-DF. Endereço para contato: SQS, I07. Bloco D, apt. 403. Asa Sul. Brasília - DF. CEP:70346-040. E-mail: alexandre-manoel.silva@ipea.gov.br.

** Técnico de Planejamento e Pesquisa do IPEA-DF. E-mail: guilherme.resende@ipea.gov.br.

$\star \star \star$ Professor Adjunto do PIMES/UFPE. E-mail: rau.silveira@uol.com.br.

(Recebido em novembro de 2006. Aceito para publicação em agosto de 2007).
} 


\section{$1 \quad$ INTRODUÇÃO ${ }^{1}$}

Nos últimos anos, percebe-se no Brasil uma elevação na rigidez orçamentária ${ }^{2} \mathrm{e}$ uma deterioração no volume de investimento público. ${ }^{3}$ Assim, tem sido recorrente o clamor por melhor qualidade e aplicação mais eficaz dos recursos públicos. No entanto, apesar da evolução técnica do Tribunal de Contas da União, órgão externo ao Poder Executivo federal e responsável pela avaliação da eficácia dos recursos públicos federais, o governo federal continua aplicando seus recursos sem a devida quantificação de sua eficácia.

De fato, no que concerne ao Poder Executivo federal, a forma usual de avaliar as despesas públicas é verificar o montante de despesa fixada na lei orçamentária anual e analisar o percentual dessa despesa que foi pago, conforme se depreende da avaliação de vários programas do Plano Plurianual (PPA) que é feita pelo Ministério do Planejamento, Orçamento e Gestão. Assim, com vistas também a mostrar a possibilidade de avaliar os recursos públicos brasileiros por meio das melhores técnicas disponíveis, este artigo analisa a eficácia do Fundo Constitucional de Financiamento do Nordeste (FNE), do Fundo Constitucional de Financiamento do Norte (FNO) e do Fundo Constitucional de Financiamento do Centro-Oeste (FCO).

Antes de iniciar essa análise, cabe uma breve explicação de como esses fundos funcionam. Do montante de arrecadação do Imposto de Renda (IR) e do Imposto sobre Produtos Industrializados (IPI), 3\% são transferidos do Tesouro Nacional para os três fundos constitucionais de financiamento. Desse total, o FNE fica com a parcela de $1,8 \%$ e os outros dois fundos (FCO e FNO) ficam cada um com uma parcela de $0,6 \%$.

Destaque-se que esses recursos são transferidos pelo Tesouro Nacional, por meio do MI (Ministério da Integração), aos bancos que efetuam operações de empréstimos, com vistas à geração de emprego e renda, que contribui para parte do crescimento da arrecadação de IR e IPI e, assim, gera uma nova receita para esses fundos. Além da receita (de IR e IPI) e do retorno das operações de empréstimos (amortização =

1 Este artigo contém os principais resultados da etapa final da avaliação dos fundos constitucionais de financiamento no convênio MI/ANPEC/IPEA. Gostaríamos de agradecer ao diretor da DIRUR, Marcelo Piancastelli, ao diretor-adjunto, Aroudo Mota e ao coordenador, Alexandre Carvalho, pela estrutura técnica e pelos incentivos fornecidos no desenvolvimento da pesquisa. Gostaríamos, também, de agradecer aos técnicos da Secretaria de Desenvolvimento Regional, no Ministério da Integração (MI).

2 Segundo estudo técnico do Ministério do Planejamento, Orçamento e Gestão (MP)/ Secretaria de Orçamento Federal (SOF) (Brasil, 2003), em 1997, as despesas de livre alocação (discricionárias) da União representavam aproximadamente $22 \%$, enquanto em 2003 somente cerca de $11 \%$ das despesas da União eram discricionárias.

3 Conforme os dados do MF/STN, em dezembro de 1998, acumulado em 12 meses, o investimento do setor público consolidado foi de 4,22\% do PIB, enquanto em dezembro de 2004 esse investimento foi de $3,54 \%$ do PIB. 
principal + juros), os juros SELIC dos valores não emprestados são as outras fontes de receita dos fundos constitucionais de financiamento.

Mesmo considerando o retorno financeiro que o FNE, o FNO e o FCO produzem aos cofres públicos da União, os recursos desses fundos representam uma parcela importante das despesas públicas. Em termos orçamentários, anualmente, esses recursos representam em torno de $0,42 \%$ da despesa primária (não-financeira) do governo federal, ou seja, cerca de $0,08 \%$ do PIB brasileiro. ${ }^{4}$

No intuito de avaliar a eficácia da aplicação desses recursos constitucionais, este artigo apresenta os resultados obtidos na avaliação da aplicação dos recursos do FNE, do FNO e do FCO no período 2000-2003, a partir das estimativas de Propensity Score das firmas beneficiadas com recursos desses fundos constitucionais e de um conjunto de firmas não-beneficiadas por esses fundos. É importante ressaltar que o objetivo inicial desta investigação, e, assim, da metodologia empregada (matching através do Propensity Score), é aferir a eficácia do programa, isto é, investigar o benefício marginal do programa, não fazendo, pois, nenhuma menção ao custo de oportunidade do programa. Também em decorrência dessa limitação, percebe-se que se trata de uma análise de estática comparativa, não sendo possível realizar nenhuma consideração sob a perspectiva de equilíbrio geral a partir dos resultados obtidos.

$\mathrm{Na}$ análise dos resultados obtidos, é importante destacar os limites presentes na avaliação, que estão vinculados tanto à natureza da avaliação, como à sua própria operacionalização. Nesse sentido, cumpre ressaltar, primeiro, que as estimativas obtidas exploram unicamente a dimensão eficácia na avaliação da aplicação dos recursos desses fundos, isto é, referem-se aos resultados econômicos dos financiamentos, o que é feito por meio do cotejo entre o desempenho econômico das firmas na situação de beneficiadas com recursos dos fundos e o desempenho de firmas na situação de não-beneficiadas com esses recursos. Dessa forma, os resultados não contêm informações diretas, por exemplo, a respeito da relação custo/benefício do número de ocupações geradas pelas firmas beneficiadas.

Uma segunda qualificação diz respeito ao universo de firmas considerado neste estudo, que, em virtude da inexistência de um conjunto de informações sobre firmas não-beneficiadas com o perfil das firmas beneficiadas, ficou restrito às firmas beneficiadas do setor formal. Em verdade, o conjunto de firmas beneficiadas utilizadas na avaliação ficou restrito àquelas efetivamente identificadas na RAIS (Relatório Anual de Informaçôes Sociais) para o período analisado. Assim, principalmente por esse

4 Essas informações estão em conformidade com as "Despesas com Subvenções aos Fundos Regionais", calculadas pela Secretaria do Tesouro Nacional, no Ministério da Fazenda. Essas despesas consideram o retorno das aplicações do FNE, FNO e FCO a partir de um cálculo de subsídios implícitos. Esse cálculo foi acordado com o Fundo Monetário Internacional em 1999. 
motivo, os resultados apresentados representam efetivamente uma avaliação parcial da eficácia da aplicação dos recursos do FNE, FNO e do FCO.

Essa última qualificação condicionou a escolha das variáveis de impacto/desempenho da avaliação, que ficaram restritas à taxa de variação do número de empregados das firmas e à taxa de variação do salário médio pago pelas firmas, variáveis passíveis de acompanhamento anual a partir da RAIS. Esta, contudo, é uma limitação menos séria que aquela representada pelo universo do setor formal, uma vez que essas são variáveis que devem estar presentes quando os objetivos de aplicação dos recursos, direta ou indiretamente, estão relacionados com a elevação da renda regional.

Embora sérios, os limites apontados acima não descredenciam a avaliação levada a efeito neste artigo, que deve ser vista como uma etapa absolutamente necessária da tarefa pioneira e imprescindível de avaliação da aplicação dos recursos desses três fundos constitucionais de financiamento.

Além desta introdução, o artigo está estruturado em mais quatro seções. Na próxima seção, é apresentada a metodologia utilizada na obtenção das estimativas do impacto dos financiamentos, o que é feito a partir da contextualização dos fundos constitucionais de financiamento dentro do problema geral de avaliação de impactos de políticas públicas. Na terceira seção, são revistas brevemente algumas experiências recentes de avaliação de eficácia de gasto público no Brasil disponíveis na literatura e que utilizam a mesma metodologia empregada neste trabalho. Na quarta seção, a mais extensa do trabalho, são apresentados os resultados das estimativas do impacto da aplicação dos recursos do FNE, FNO e FCO sobre as firmas beneficiadas a partir de suas taxas de crescimento do emprego e dos salários pagos. Essas variáveis são tomadas como referências para a avaliação da política para as firmas no período 2000-2003. Além desses resultados, por representar um subgrupo ${ }^{5}$ de interesse específico dos Fundos, estimativas adicionais são obtidas para as firmas de micro e pequenos portes (até 49 empregados). Na quinta e última seção, além de algumas conclusões a respeito dos resultados da avaliação, é feita uma comparação entre os resultados obtidos na avaliação do FNE, do FNO e do FCO, e são apresentadas hipóteses explicativas para os distintos resultados regionais obtidos.

5 É válido destacar que seria importante estudar outros subgrupos; contudo, em virtude da limitação de observações disponibilizadas, isso não foi possível. 


\section{METODOLOGIA APLICADA NA AVALIAÇÃO DO IMPACTO DOS FUN- DOS CONSTITUCIONAIS DE FINANCIAMENTO}

A questão da avaliação do impacto da aplicação dos recursos do FNE, do FNO e do FCO sobre as firmas beneficiadas deve ser vista dentro da problemática geral de avaliação dos impactos de políticas públicas. Nessas situações, de forma geral, as dificuldades derivam da impossibilidade da observação simultânea do indivíduo/ firma em situações ou estados da natureza diferentes, i.e, beneficiado e não- beneficiado pela política. Ou seja, as técnicas tentam resolver o problema de avaliação sob insuficiência de informações a respeito dos beneficiados.

Para uma rápida formalização dessa situação, considere-se um indivíduo/firma $i$, uma variável de avaliação de impacto $Y$ (taxa de crescimento do emprego, por exemplo) e os dois estados possíveis, " $\mathrm{l}$ " para a situação de ter sido beneficiado e " 0 " para a situação de não ter sido beneficiado. Com $D=1$ indicando o primeiro estado, por exemplo, firma financiada pelo $\mathrm{FNE}$, e, $D=0$, por exemplo, firma não-financiada pelo FNE. O resultado observado para a variável de interesse da política, $Y$ da firma/ indivíduo $i$, pode ser representado por:

$$
Y^{i}=D Y_{1}^{i}+(1-D) Y_{0}^{i}
$$

de modo que o impacto da política para o indivíduo/firma $i$ e o impacto médio da política sobre as firmas beneficiadas podem ser representados, respectivamente, por $\Delta^{i}=Y_{1}^{i}-Y_{0}^{i}$ e $\Delta=E\left(\Delta^{i} / D=1\right)=E\left(Y_{1}^{i}-Y_{0}^{i} / D=1\right)$, em que $E(. / D=1)$ refere-se ao valor esperado condicionado à participação no financiamento.

Como não é possível observar as firmas/indivíduos nas duas situações simultaneamente, utiliza-se nas avaliações um grupo de indivíduos que não recebeu o benefício, grupo de controle, obtendo-se uma medida aproximada do impacto do benefício sobre a variável considerada:

$$
\begin{aligned}
& E\left(Y_{1}^{i} / D=1\right)-E\left(Y_{0}^{j} / D=0\right)=E\left(Y_{1}^{i} / D=1\right)-E\left(Y_{0}^{i} / D=1\right)+E\left(Y_{0}^{i} / D=1\right)-E\left(Y_{0}^{j} / D=0\right) \\
& =\Delta+\left[E\left(Y_{0}^{i} / D=1\right)-E\left(Y_{0}^{j} / D=0\right)\right]
\end{aligned}
$$

A diferença dentro dos colchetes, diferença entre os valores esperados da variável quando da não- participação no programa condicionado aos dois estados, corresponde à medida do erro que é gerada ao se utilizar o grupo de controle. Esse erro 
deriva do fato de que, por exemplo, a taxa de crescimento do emprego das firmas do grupo de controle não corresponde àquela dos beneficiados caso não tivessem recebido o financiamento. Assim, essa medida fornece um indicador do viés de seleção ou participação na política, associado ao fato de que a própria participação no financiamento serve, em si, para diferenciar as firmas (mais motivadas versus menos motivadas, por exemplo).

Dessa forma, percebe-se que a precisão e o grau de identificação do impacto do programa sobre as firmas beneficiadas, $\Delta$, dependem do tamanho do viés de seleção envolvido na avaliação. Essa magnitude, por sua vez, está vinculada ao mecanismo de seleção do grupo de controle e às técnicas de avaliação utilizadas nessa tarefa.

No caso do presente estudo, se fosse possível realizar uma seleção aleatória entre beneficiados e não-beneficiados (pelo financiamento), ter-se-ia um verdadeiro experimento social, ${ }^{6}$ de modo que os resultados da política não guardariam relação com a disposição a participar ou não da política. Em outras palavras, ter-se-ia $E\left(Y_{0}^{i} / D=1\right)-E\left(Y_{0}^{j} / D=0\right)=0$. Nesse caso, $\Delta$ poderia ser prontamente estimado por meio da diferença entre os valores esperados para os dois grupos do mesmo universo:

$$
\Delta=E\left(Y_{1}^{i} / D=1\right)-E\left(Y_{0}^{j} / D=0\right)
$$

$\mathrm{Na}$ ausência de um grupo de controle aleatório, de forma geral, os indivíduos/firmas do grupo de comparação são escolhidos segundo algumas características previamente elegíveis, tidas como fundamentais para a dinâmica da variável fim do programa (taxa de crescimento do emprego, por exemplo). Adicionalmente, são empregados diferentes estimadores na mensuração do impacto dos programas nos beneficiados, dependentes do conjunto de informações disponíveis, da variável em análise e das hipóteses assumidas sobre a participação no programa de treinamento. Em seguida, são apresentados os estimadores utilizados neste estudo. ${ }^{7}$

\subsection{Diferença das Médias sem Controle}

A estimativa do impacto do programa sobre os beneficiados por meio da diferença das médias da variável fim ou de interesse assume, arbitrariamente, que não existem

6 Para um survey desta literatura ver, por exemplo, Friendlander, Greenberg e Robins (1997).

7 Não é discutida, aqui, em particular, a possibilidade da utilização do estimador de Mínimos Quadrados Ordinários para obtenção de estimativas do impacto do programa sobre firmas beneficiadas em função da restrição imposta pela necessidade da assunção de uma função específica (linear) para relação entre as covariadas e a variável de interesse. Ver, a respeito, Wooldridge (2002). 
diferenças importantes entre beneficiados e grupo de controle em relação às características importantes para explicação do comportamento da variável de interesse. O impacto do programa sobre os beneficiados é estimado calculando-se a diferença entre as médias dessa variável para os beneficiados e o grupo de controle, observando-se então a sua significância estatística (teste de diferenças de médias).

Especificamente, o impacto do programa $(\Delta)$ é aproximado por:

$$
E\left(Y_{1}^{i} / D=1\right)-E\left(Y_{0}^{j} / D=0\right)=E\left(Y_{t}^{i}\right)-E\left(Y_{c}^{j}\right)
$$

em que $i$ e $j$ referem-se aos indivíduos de cada grupo e $Y_{t}^{i}, Y_{c}^{j}$ referem-se, respectivamente, aos valores da variável para indivíduos dos grupos de beneficiados e controle. Mesmo sob a suposição de que características importantes das firmas para a variável de interesse sejam aproximadas entres os dois grupos, dificilmente essa estimativa fornece um valor confiável para o impacto da política, pois a própria participação no programa já pode sinalizar diferenças importantes entre os indivíduos/firmas dos dois grupos.

\subsection{Estimadores com Matching Baseados no Propensity Score}

Uma alternativa às dificuldades acima apontadas é a utilização de um estimador de matching que, ao assumir que a seleção para o programa se dá apenas a partir de características observáveis, obtém o efeito do financiamento considerando subgrupos de indivíduos/firmas. ${ }^{8}$

Uma vez que as firmas com características observáveis idênticas $(X)$ tenham a mesma probabilidade de serem escolhidas para os grupos de financiamento e de controle, o valor da variável de interesse $(Y)$, dadas as informações em $(X)$, passa a ser estatisticamente independente do estado. Formalmente, nessa situação, tem-se $\left(Y_{1}^{i}, Y_{0}^{j} \perp D_{0,1}\right) / X$ e assim, da equação (2),

$$
E\left(Y_{0}^{i} / X, D=1\right)-E\left(Y_{0}^{j} / X, D=0\right)=0
$$

em queo símbolo $\perp$ indica independência.

8 Para uma discussão detalhada deste estimador, ver Angrist e Krueger (1999). 
Dessa forma, o impacto do financiamento sobre as firmas $(\Delta)$ pode ser calculado para as firmas com características observáveis idênticas, isto é, de acordo com a equação (2):

$$
\Delta_{z}=E\left(Y_{1}^{i} / X, D=1\right)-E\left(Y_{0}^{j} / X, D=0\right)
$$

em que $\Delta_{z}$, dado pela diferença entre as médias da variável de interesse para beneficiados e controles com características observáveis idênticas, corresponde ao impacto médio do programa nas firmas com características $X$ (idênticas). Porém, existe dificuldade em implementar esse estimador quando há um número muito grande de variáveis $X$ ou quando essas são contínuas.

Os métodos de Propensity Score procuram sintetizar as informações contidas nas variáveis em $X$, que afetam a participação na obtenção do financiamento. Isso é feito por meio da estimação, condicionada nessas variáveis, da probabilidade de pertencer ao grupo de treinamento (estimativa de propensity score). Assim, em vez de utilizar as variáveis $X$ diretamente, utilizam-se as probabilidades de participação derivadas delas.

Não obstante, para a aplicação desse método, é necessário que as propriedades estatísticas dos resultados para a variável de interesse $(Y)$ em relação a $D$ e $X$, acima assumidas, sejam válidas também quando, em vez de $X$, considera-se $\operatorname{Pr}(X)$, probabilidade de participação determinada pelas variáveis em $X$. Nesse sentido, Rosenbaum e Rubin (1983) mostram que, se $\left(Y_{1}^{i}, Y_{0}^{j} \perp D_{0,1}\right) / X$, então $\left(Y_{1}^{i}, Y_{0}^{j} \perp D_{0,1}\right) \operatorname{Pr}(X)$, em que $\operatorname{Pr}(X)=\operatorname{Pr}(D=1 \mid X)$.

O que permite reescrever a equação (6) como:

$$
\Delta_{p}=E\left(Y_{1}^{i} / \operatorname{Pr}(X), D=1\right)-E\left(Y_{0}^{j} / \operatorname{Pr}(X), D=0\right)
$$

Ao menos quatro diferentes tipos de matching baseados nas estimativas de propensity score podem ser identificados na literatura empírica de avaliação de impacto de políticas públicas ou programas de treinamento (DEHEJIA; WAHBA, 2002 e BECHER; ICHINO, 2002): o matching a partir de grupos ou estratos (Stratification Matching), o matching a partir do vizinho mais próximo (Nearest Neighbor Matching), o matching a partir de vizinhos dentro de um raio fixo (Radius Matching) e o matching a partir de uma função densidade (Kernel Matching). Uma vez que não é possível identificar uma ordem de superioridade quanto às propriedades estatísticas entre 
essas alternativas, e dada a obtenção de resultados bastante próximos para todas as quatro formas de matching, neste artigo são apresentados apenas os resultados obtidos especificamente para os estimadores de matching a partir de grupos ou estratos (Stratification Matching) e de matching a partir de uma função densidade (Kernel Matching). ${ }^{9}$

O matching a partir de estratos ou grupos considera a comparação entre as médias da variável de interesse dos beneficiados e não-beneficiados pela política pública nos respectivos estratos, nos quais as firmas dos dois grupos apresentam em média a mesma estimativa de propensity score. Assim, estimam-se as probabilidades de participações, isto é, o propensity score para as firmas. Em seguida, essas firmas são agrupadas de acordo com essas probabilidades. O resultado final representa uma soma ponderada das diferenças das médias das variáveis de interesse $(Y)$ para cada estrato, com os pesos dados pela participação dos beneficiados em cada estrato.

Formalmente, considere-se a distribuição de beneficiados e não-beneficiados pela política pública em $m$ estratos, de forma que a média das estimativas de propensity score para os dois grupos não apresente diferença estatisticamente significante em cada estrato. Se $Y$ é a variável de interesse, o primeiro passo é computar as diferenças de desempenhos entre os beneficiados e não-beneficiados dentro de cada estrato:

$$
\Delta_{e}^{S}=\frac{\sum_{i \in S(e)} Y_{i}^{B}}{N_{e}^{B}}-\frac{\sum_{j \in S(e)} Y_{j}^{N B}}{N_{e}^{N B}} \quad \mathrm{e}=1,2, \ldots ., \mathrm{m}
$$

em que $S(e)$ especifica o conjunto de firmas do estrato $e, Y_{i}^{B}$ e $Y_{j}^{N B}$ correspondem aos resultados observados para as firmas $i$ e $j$, respectivamente, dos grupos dos beneficiados e não-beneficiados (controle) no estrato e $N_{e}{ }^{B}$ e $N_{e}{ }^{N B}$ correspondem aos respectivos números de firmas nesse mesmo estrato. Nesse caso, o resultado final da avaliação do impacto da política pública $\left(\Delta^{S}\right)$ é computado a partir de uma média ponderada desses $m$ resultados obtidos para os estratos:

$$
\Delta^{S}=\sum_{e=1}^{m} \Delta_{e}^{S} \frac{N_{e}^{B}}{N^{B}}
$$

Apesar de comparar firmas com médias de probabilidades de participações próximas em cada grupo, o matching a partir de estratos não garante a utilização de todas as

9 Para uma discussão quanto às propriedades estatísticas dos diferentes critérios para o matching, ver Becker e Ichino (2002) e Rosenbaum (2002). Os resultados obtidos para o matching a partir do vizinho mais próximo e para o matching a partir de vizinhos dentro de um raio fixo podem ser disponibilizados pelos autores. 
observações (firmas) disponíveis, uma vez que é possível que não-beneficiados do grupo de comparação estejam ausentes em alguns estratos.

O matching a partir de uma função densidade ou Kernel Matching representa uma ampliação do universo de comparação de cada beneficiado na medida em que os beneficiados são individualmente cotejados com todas as observações do grupo de controle (não-beneficiados), ponderando-se esse cotejo por meio da distância entre as observações do beneficiado e do não-beneficiado. Essa distância é estimada por meio de uma função densidade que a calcula conforme as estimativas de propensity score. Novamente, o resultado final do impacto da política é obtido a partir de uma média das comparações entre beneficiados e não-beneficiados, ponderando-se pelo número de beneficiados.

Formalmente, considerando-se uma função kernel $G($.$) e um parâmetro para janela$ $h$, para cada observação $i$ de firmas beneficiadas pela política pública (cada $i \in B$ ) é estimada a seguinte média ponderada dos resultados $Y_{j}^{N B}$ observados (considerandose todas as firmas do grupo de controle, isto é, todo $j \in N B$ ):

$$
Y_{k i}^{N B}=\frac{\sum_{j \in N B} Y_{j}^{N B} G\left(\frac{p_{j}-p_{i}}{h}\right)}{\sum_{l \in N B} G\left(\frac{p_{l}-p_{i}}{h}\right)} \quad i \in B
$$

Dessa forma, a estimativa do impacto da política $\left(R^{K}\right)$ é obtida a partir da média das diferenças entre $Y_{i}^{B}$ e $Y_{k i}^{N B}$, isto é:

$$
\Delta^{K}=\frac{1}{N^{B}} \sum_{i \in B}\left[Y_{i}^{B}-Y_{k i}^{N B}\right]
$$

Deve estar claro, pois, que os estimadores que utilizam as estimativas de propensity score permitem solucionar o problema da execução do balanceamento (match) entre firmas/indivíduos quando o número de variáveis observáveis é muito elevado. Todavia, não opera sem limitações; em particular, é importante apontar que não soluciona problemas relacionados com o potencial viés de participação derivado da influência de variáveis não-observáveis. Além disso, nem sempre há garantias antecipadas de existência de firmas/indivíduos comparáveis, mesmo quando a participação é condicionada apenas em variáveis observáveis. 


\section{AVALIAÇÃO DA EFICÁCLA DO GASTO PÚBLICO NO BRASIL: A EXPE- RIÊNCIA RECENTE}

Este artigo tem como objetivo fornecer informações sobre a aplicação de recursos públicos em favor de agentes privados pré-selecionados. Nesse sentido, deve ser visto como mais uma contribuição para a recente experiência brasileira na avaliação da eficácia da alocação de recursos públicos.

Para contextualizar a investigação efetivada na literatura econômica brasileira sobre avaliação de políticas públicas, ainda que em diferentes contextos, é possível identificar ao menos três trabalhos que utilizam especificamente a metodologia apresentada na segunda seção deste trabalho.

Ao focar o impacto dos programas públicos de treinamento dos trabalhadores em situação economicamente desvantajosa no Estado de Pernambuco, mais especificamente, o antigo PLANFOR do Ministério do Trabalho e Emprego, Silveira Neto (2002) utiliza estimadores de propensity score para avaliar em que medida os trabalhadores treinados, quando cotejados com aqueles não-treinados, apresentavam melhor desempenho no mercado de trabalho em termos de renda ou probabilidade de estarem empregados. Consistentes com o desaparecimento do programa, os resultados obtidos pelo autor não indicaram nenhum desempenho superior por parte dos indivíduos que haviam participado dos treinamentos e cursos.

A partir de matching nas estimativas de propensity scove e ainda tendo como foco o Estado de Pernambuco, centrando-se, no entanto, na avaliação da aplicação dos recursos do PRONAF (Programa Nacional de Fortalecimento da Agricultura Familiar) sobre o desempenho econômico das famílias e agricultores beneficiários, Magalhães et.al. (2006), a partir de microdados referentes ao período de 1998 a 2001, não encontram substanciais impactos positivos da aplicação dos recursos sobre o valor da produção e valor da produção por hectare dos diferentes grupos do PRONAF. De fato, apenas para os agricultores pertencentes ao grupo com valor da renda bruta anual intermediária (grupo C) é obtida uma estimativa positiva da aplicação dos recursos, ainda assim, apenas sobre o valor da produção por trabalhador.

Por sua vez, atendo-se à recente política pública de transferência de renda do governo federal consubstanciada no Bolsa-Família, Resende e Oliveira (2006) fazem uso do matching nas estimativas de propensity scove a partir de dados da POF (Pesquisa de Orçamento Familiar) de 2002-2003 para avaliar o impacto da transferência de renda sobre os gastos das famílias brasileiras. Os resultados obtidos apontam para um efeito positivo das transferências de recursos sobre a despesa familiar, ou seja, os 
níveis de despesa das famílias beneficiadas encontram-se acima dos níveis relativos às não-beneficiadas, mas também elegíveis para o programa.

Dentro desse panorama, ao contrário das demais avaliaçốes, cujos focos eram indivíduos, famílias ou firmas beneficiadas por programas públicos presentes em diferentes regiốes do País, a especificidade da investigação ora levada a efeito diz respeito ao critério geográfico ou regional da política pública e, assim, da avaliação. Nesse sentido, a investigação representa um esforço pioneiro de avaliação de eficácia de políticas de desenvolvimento regional no Brasil a partir de microdados de firmas beneficiadas, sendo essa condição vinculada à localização geográfica no País.

\section{AVALIAÇÃO DOS FUNDOS CONSTITUCIONAIS DE FINANCIAMENTO}

Nesta seção, são apresentadas as estimativas dos impactos das aplicações dos recursos do Fundo Constitucional de Financiamento do Nordeste (FNE), do Fundo Constitucional de Financiamento do Norte (FNO) e do Fundo Constitucional de Financiamento do Centro-Oeste (FCO) sobre o desempenho das firmas beneficiadas das respectivas macrorregiões brasileiras. Como já adiantado na introdução deste trabalho, as informações utilizadas nas avaliações da eficácia dos três Fundos foram obtidas a partir da identificação de firmas beneficiadas e não-beneficiadas com os empréstimos desses fundos nas respectivas regiões.

Três diferentes bancos de dados para as respectivas regiões foram constituídos, a partir de informações sobre as firmas beneficiadas obtidas junto aos agentes bancários que administram os três Fundos (Banco do Nordeste do Brasil, no caso do FNE, o Banco da Amazônia, no caso do FNO, e o Banco do Brasil, no caso do FCO) e da posterior identificação dessas firmas na RAIS.

Apesar de conterem as mesmas informações sobre as firmas nas três regiões para o mesmo período (2000 a 2003), por razões legais e estruturais foram obtidas estimativas em separado para cada Fundo. Entre as razões legais, destaque-se que, no caso do FNE, metade dos recursos deve ser investida no semiárido da região Nordeste. ${ }^{10}$ Entre as razões estruturais, ressalte-se que os empréstimos são feitos por diferentes agentes bancários, os quais, por sua vez, dispõem de diferentes conselhos de administração; implicando, portanto, substanciais diferenças de gerenciamento de recursos pelos diferentes bancos.

10 Além dessa razão legal, ressalte-se que, eventualmente, por mecanismos legais, são concedidos abate ou equalização de maneira não uniforme entre FNE, FCO e FNO. Isso, em alguma medida, deve ajudar na diferenciação da concessão de empréstimos entre esses fundos. 
Além disso, a título de ilustração, no ano de 2000, o total de recursos contratados pelo FNO foi cerca de $45 \%$ do total contratado para os três Fundos, percentual bem acima da distribuição pré-estabelecida pela legislação para a região Norte (um sexto do total da renúncia fiscal) e acima daquele contratado pelo FNE para a região Nordeste (que deve ficar com dois terços da renúncia fiscal total).

Dessa forma, além de potencialmente elevar o número de variáveis não-observáveis ou observáveis de difícil mensuração, a estimação conjunta a partir das observações dos três bancos de dados não refletiria nem a estrutura institucional nem a partitha regular dos recursos contratados entre os Fundos, gerando informação menos relevante. Na próximas subseçóes são apresentados, pois, os resultados obtidos das estimativas para o FNE, FNO e FCO, nessa ordem.

\subsection{Fundo Constitucional de Financiamento do Nordeste - FNE}

O interesse inicial é conhecer ou obter informações estatisticamente válidas a respeito do impacto do FNE sobre as firmas beneficiadas. Nessa direção, os dados disponíveis possibilitaram focar a avaliação em duas variáveis de interesse imediato do FNE: a taxa de variação do emprego e a taxa de variação dos salários médios pagos pelas firmas.

Destaque-se que a primeira variável corresponde a um objetivo explícito dos financiamentos (geração de postos de trabalho), enquanto a segunda, além de corresponder à geração de renda ou valor agregado, pode representar uma boa proxy para mensurar impactos sobre a produtividade, outro objetivo explícito do FNE. Ademais, em virtude de ser possível que ganhos de produtividade impliquem perdas de emprego, ao menos no curto prazo, a consideração conjunta dessas duas variáveis permite, adicionalmente, uma avaliação mais consistente da aplicação dos recursos do FNE.

É válido ressaltar os limites e abrangência desta avaliação. Nesse sentido, note-se, primeiro, que os financiamentos avaliados correspondem àqueles tomados pelas firmas no ano de 2000, a partir do qual as firmas foram acompanhadas, com novas evidências a respeito das dinâmicas das variáveis de interesse levantadas, novamente, para o ano de 2003.

Há, pois, para as duas variáveis supramencionadas, o seguinte período de avaliação: 2000-2003. Além disso, a avaliação restringe-se às empresas tomadoras dos recursos do FNE identificadas na RAIS de 2000. Por fim, em virtude de maior prioridade, além de evidências para todo o conjunto de firmas beneficiadas identificadas na 
RAIS, foi obtido um conjunto adicional de evidências para o subgrupo de micro e pequenas firmas.

\subsubsection{Dados e Evidências Iniciais}

As estimativas apresentadas foram obtidas a partir de duas diferentes amostras. Uma primeira amostra é constituída pelas firmas beneficiadas pelo FNE no ano de 2000 da região Nordeste e que foram identificadas na RAIS desse mesmo ano. Das 254 firmas beneficiadas pelo FNE em 2000, foi possível identificar 231 firmas, das quais foram excluídas as firmas que também receberam financiamento nos anos de 2001, 2002 e 2003. Assim, a amostra de beneficiadas é constituída por 211 firmas da região Nordeste do País. A partir do universo de firmas presentes na região Nordeste, na RAIS, em 2000, uma outra amostra de 1.234 firmas, que não receberam financiamento do FNE em nenhum dos anos do período analisado, foi considerada para o grupo de comparação ou controle. ${ }^{11}$

$\mathrm{Na}$ busca de robustez nas estimativas, foram discutidas estimativas sem controle para a probabilidade de beneficiar-se por meio do financiamento via FNE e, também, dois estimadores de propensity score, que foram discutidos na seção anterior: o match de desempenhos entre firmas beneficiadas e não-beneficiadas a partir de estratos e a comparação a partir da utilização de um kernel, o que implica a comparação de cada firma beneficiada com todas as demais não-beneficiadas, com pesos dados pela distância entre as estimativas de propensity score da firma beneficiada e das nãobeneficiadas.

As estimativas propensity score são basicamente levadas a efeito em duas etapas. $\mathrm{Na}$ primeira, a partir de um modelo probit ou logit ${ }^{12}$ e de características observáveis das firmas, estima-se a probabilidade de cada firma ser beneficiada com recursos do FNE. Em uma segunda etapa, essas estimativas são utilizadas para comparações ponderadas entre beneficiadas e não-beneficiadas pelo FNE. Na estimação a partir de estratos, essa segunda etapa consiste no agrupamento de firmas em estratos em que beneficiadas e não-beneficiadas, além de apresentarem estimativas de probabilidades próximas, são idealmente indistinguíveis com respeito às variáveis observadas e utilizadas na estimação. ${ }^{13} \mathrm{Na}$ estimação com utilização de um kernel, cada firma beneficiada é comparada com as demais não-beneficiadas, em uma comparação que é ponderada pela distância entre as estimativas de propensity score.

11 As características e comparação entre as amostras são descritas a seguir.

12 No caso deste artigo, as estimativas em geral não são sensíveis à utilização alternativa de um dos dois modelos.

13 Tecnicamente, a exigência é que, dentro de cada estrato, a condição de ser beneficiada ou não-beneficiada pelo FNE seja independente das variáveis observadas e consideradas na estimação. 
Uma descrição das variáveis consideradas nas estimativas e uma comparação das características das duas amostras utilizadas são possíveis a partir dos números presentes na Tabela 1. Nesse sentido, ressalte-se que no exercício investigativo foram utilizadas todas as variáveis disponíveis na RAIS que pudessem caracterizar o perfil das firmas e condicionar sua decisão de participar como beneficiárias do financiamento. Assim, tanto no caso do FNE, como nos casos do FNO e FCO, foram utilizadas variáveis que caracterizam o perfil da demanda por trabalho das firmas (escolaridade e idade da força de trabalho), o porte das firmas (número de empregados e nível salarial), ${ }^{14}$ seu ramo de atividades e sua localização geográfica. Por fim, apenas foram utilizadas firmas que, antes de 2000, não haviam tomado nenhum financiamento do FNE. ${ }^{15}$

A partir das evidências a seguir, em 2000, com respeito ao perfil das firmas beneficiadas e não-beneficiadas com recursos do $\mathrm{FNE}$, ao menos algumas características merecem destaque. Primeiramente, as firmas beneficiadas apresentam maior concentração de trabalhadores nos níveis intermediários de escolaridade. Por sua vez, as firmas RAIS não-beneficiadas apresentam-se mais bem distribuídas de acordo com os diferentes níveis de escolaridade de sua força de trabalho. Particularmente importante, enquanto $35,5 \%$ das firmas RAIS não-beneficiadas apresentam sua força de trabalho em média com segundo grau ou mais, as firmas beneficiadas pelo FNE apresentam tal percentual em torno de $12,3 \%$.

Não há diferenças importantes entre os dois conjuntos de firmas quanto à idade média dos empregados nem quanto ao porte das firmas. Mais especificamente, para ambas as amostras, mais de $\mathbf{8 6 \%}$ das firmas podiam ser classificadas com micro ou pequena $^{16}$ (até 49 empregados). Esse fato, ainda que refletida a própria distribuição das firmas das RAIS, parece estar de acordo com o foco e com objetivos do programa, ao menos quando se considera a escala das firmas beneficiadas (micro e pequenos produtores).

A despeito da semelhança entre os dois grupos de firmas quanto ao porte, há diferenças significativas entre os dois grupos de firmas quanto ao salário médio pago aos empregados. De fato, os números da Tabela 1 indicam que os salários pagos pela firmas não-beneficiadas eram em média 16,4\% maiores que aqueles pagos pelas firmas beneficiadas pelo FNE. Essa evidência é consistente com a maior presença das firmas não-beneficiadas no grupo de empregados com maior escolaridade, o que pode indicar situação economicamente mais frágil (mais baixa produtividade) das firmas beneficiadas.

14 Infelizmente, por não ser uma informação disponível na RAIS, não foi possível utilizar o faturamento das firmas como condicionante à participação como beneficiária dos financiamentos.

$15 \mathrm{O}$ que também se aplica imediatamente para os casos do FCO e FNO.

16 A definição de micro/pequena empresa e médio/grande porte seguiu a definição do SEBRAE. 
TABELA 1 - PERFIS DAS FIRMAS BENEFICIADAS PELO FNE E DAS FIRMAS NÃO-BENEFICIADAS DA RAIS - 2000

\begin{tabular}{|c|c|c|}
\hline Variável & FNE formal & RAIS \\
\hline \multicolumn{3}{|l|}{ Grau médio de instrução(\%) } \\
\hline Analfabeto ou da $1^{a}$ à $4^{a}$ série incompleta* & 6,6 & 12,9 \\
\hline $1^{\mathrm{a}}$ até $4^{\mathrm{a}}$ série completa & 8,5 & 10,6 \\
\hline $5^{\mathrm{a}}$ até $8^{\mathrm{a}}$ série incompleta* & 18,0 & 13,0 \\
\hline $8^{a}$ série completa* & 34,6 & 15,4 \\
\hline $2^{\circ}$ grau incompleto* & 19,9 & 12,5 \\
\hline $2^{\circ}$ grau completo ou mais $^{\star}$ & 12,3 & 35,5 \\
\hline Idade média dos empregados (anos) & 31,5 & 32,8 \\
\hline \multicolumn{3}{|l|}{ Número de empregados (\%) } \\
\hline Micro e Pequeno porte (até 49 empregados) & 86,7 & 86,6 \\
\hline Médio e Grande porte (mais de 49 empregados) & 13,3 & 13,4 \\
\hline Salário médio em Salário Mínimo* & 2,07 & 2,41 \\
\hline \multicolumn{3}{|l|}{ Grupo CNAE (\%) } \\
\hline Agropecuária* & 14,7 & 5,5 \\
\hline Indústria* & 54,5 & 16,9 \\
\hline Comércio* & 24,2 & 40,6 \\
\hline Serviços* & 6,6 & 36,7 \\
\hline \multicolumn{3}{|l|}{ Estados do Nordeste (\%) } \\
\hline Maranhão & 7,6 & 5,6 \\
\hline Piauí ${ }^{*}$ & 9,5 & 4,0 \\
\hline Ceará & 15,6 & 15,2 \\
\hline Rio Grande do Norte & 6,6 & 6,3 \\
\hline Paraíba* & 10,4 & 5,7 \\
\hline Pernambuco* & 12,3 & 17,8 \\
\hline Alagoas & 4,3 & 4,4 \\
\hline Sergipe ${ }^{*}$ & 11,8 & 4,9 \\
\hline Bahia* & 12,8 & 30,0 \\
\hline
\end{tabular}

Fonte: Estimativas dos autores a partir de dados da RAIS e do BNB.

Nota: “* ” indica significância estatística a 5\% para os testes de diferenças entre médias e entre proporções entre os dois grupos, o que implica rejeição das correspondentes hipóteses nulas de que as médias ou proporções são iguais.

É possível, também, apontar diferenças significativas entre a distribuição das firmas beneficiadas e não-beneficiadas pelo FNE, de acordo com os grandes setores. Como reflexo dos focos do programa de financiamento, percebe-se que a maior parte das firmas beneficiadas pertence aos setores agropecuário e industrial (quase 70\%), en- 
quanto as firmas não-beneficiadas são, sobretudo, vinculadas aos setores do comércio e serviços (em torno de $77 \%$ ).

No que concerne à distribuição das firmas beneficiadas entre os estados da região, que tende a refletir as diferenças de porte econômico entre os Estados, também é possível apontar diferenças marcantes em relação àquela distribuição encontrada para as firmas não-beneficiadas da RAIS. Especificamente, é possível apontar três Estados com sobrerrepresentações (Piauí, Paraíba e Sergipe), isto é, com números de firmas beneficiadas relativamente maiores que aqueles esperados de acordo com a distribuição das firmas entre os Estados encontrada de forma geral na RAIS, e dois Estados com sub-representaçôes (Bahia e Pernambuco), ou seja, com números de firmas beneficiadas relativamente menores que aqueles esperados segundo suas respectivas presenças na RAIS.

A partir das estimativas dos coeficientes do modelo probit para cada firma das duas amostras, ${ }^{17}$ foram obtidas estimativas relativas à probabilidade de ser beneficiada pelo FNE. Essas estimativas foram utilizadas para obter as estimativas de propensity score do FNE. Para se ter uma idéia das probabilidades estimadas, a partir dos correspondentes histogramas na Figura 1, são apresentadas as respectivas distribuições dessas probabilidades para os dois conjuntos de firmas, não-beneficiadas (0) e beneficiadas (1).

Dados os objetivos explícitos do programa, com maior foco nas pequenas e micro firmas e nas firmas dos setores industrial e agropecuário, as estimativas da Figura 1 indicam que, de fato, uma amostra aleatória de firmas das RAIS implica a obtenção de baixas probabilidades de participação para maior parte do conjunto de firmas. Mais especificamente, nota-se que a maior parte das firmas da amostra RAIS apresenta probabilidade de participação no FNE entre 0 e $20 \%$, enquanto para as firmas beneficiadas a maior parte apresenta probabilidade de participação acima de $20 \%$. Essas diferenças apontam para a importância de se considerar, na estimativa do impacto do financiamento sobre a firma beneficiada, apenas comparações entre firmas com probabilidades de participação semelhantes.

17 Nessa tarefa, é utilizada a extensão pscore.do do programa Stata 8.0 devida a Becher e Ichino (2002). 
FIGURA 1 -DISTRIBUIÇÕES DAS PROBABILIDADES DE PARTICIPAÇÃO ESTIMADAS

Prob. de particip. no FNE

0

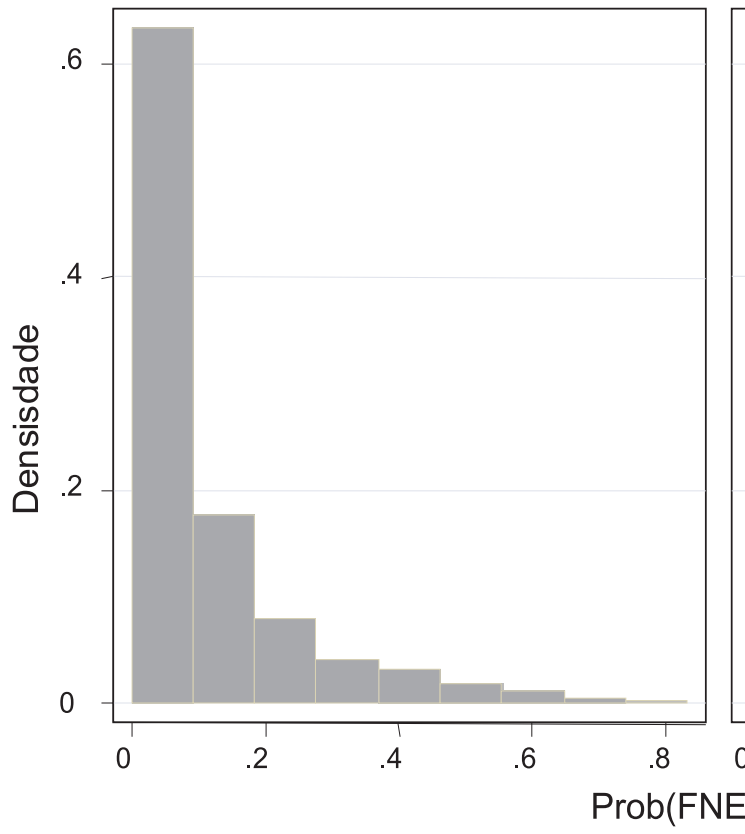

Prob. de particip. no FNE 1

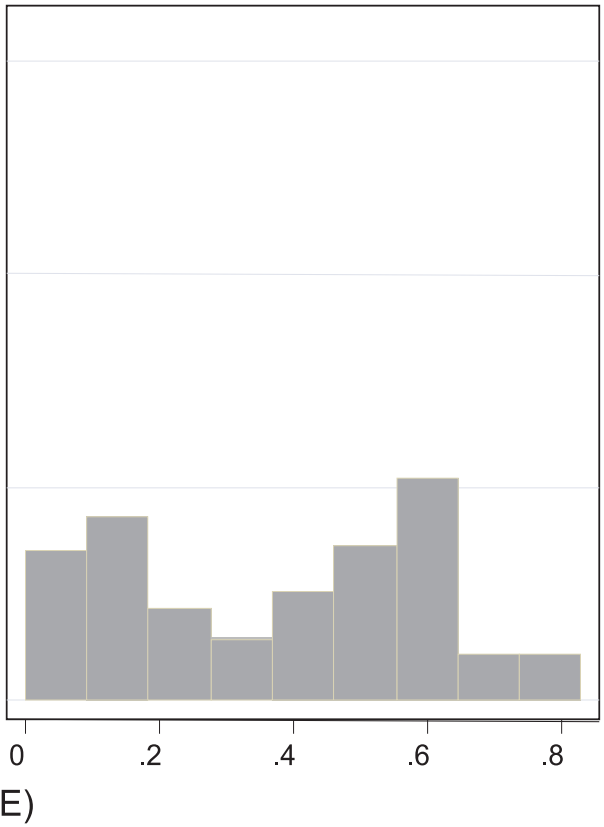

Graphs by fne

Fonte: Elaboração dos autores.

\subsubsection{Impacto do FNE nas Firmas Beneficiadas: Estimativas Gerais}

No caso da estimação a partir de estratos, foi possível obter oito estratos, nos quais tanto as estimativas de probabilidade como as demais variáveis encontram-se balanceadas entre os dois conjuntos de firmas. Para uma rápida percepção da distribuição das firmas entre os oito estratos, a Figura 2 apresenta as distribuições das firmas beneficiadas (FNE) e da RAIS entre esses estratos.

Observe que grande parte das firmas RAIS encontra-se no primeiro estrato (entre $0,0$ e 0,05$)$ e a maior parte das firmas beneficiadas encontra-se nos estratos acima de 0,2 para probabilidade de participação. Apesar de existirem essas diferenças, o importante a reter é que as comparaçôes a partir de estratos consideram as diferenças de desempenho apenas a partir da comparação das firmas dos dois grupos em um mesmo estrato. 
FIGURA 2 - DISTRIBUIÇÃO DAS FIRMAS ENTRE OS ESTRATOS

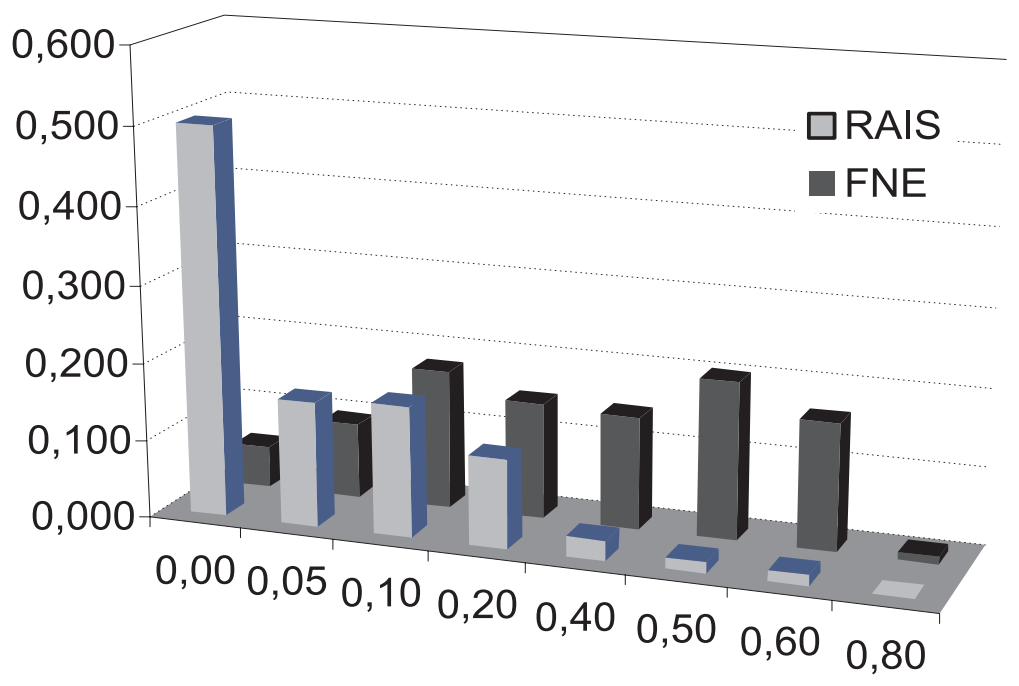

Estratos com probab. de participação

Fonte: Elaboração dos autores.

A Tabela 2 apresenta as estimativas de Propensity Score para o impacto do financiamento do FNE sobre as firmas beneficiadas, tomando-se para isso as taxas de variação do emprego e do salário médio pago pelas firmas. Nessas duas variáveis, estima-se a diferença média entre a situação quando beneficiada pelo FNE e a situação caso não tivesse sido beneficiada pelo programa. A Tabela 2 também apresenta aquela estimativa resultante apenas da comparação entre as médias de desempenho das firmas beneficiadas pelo FNE e das firmas RAIS entre 2000 e 2003, quando não é feito nenhum controle para a probabilidade de participação (Sem Controle). 
TABELA 2 - IMPACTO DO FNE: DIFERENÇAS ENTRE TAXAS DE VARIAÇÃO DO EMPREGO E DO SALÁRIO MÉDIO NO PERÍODO 2000-2003

\begin{tabular}{lcc}
\hline & Taxa de variação Emprego & Taxa de variação Salário Médio \\
\hline \multirow{2}{*}{ Sem Controle } & $0,557^{\star}$ & 0,014 \\
& $(0,208)$ & $(0,026)$ \\
Propensity Score - Estratos & $0,651^{*}$ & $-0,013$ \\
& $(0,217)$ & $(0,038)$ \\
Propensity Score - Kernel & $0,612^{*}$ & $-0,003$ \\
& $(0,217)$ & $(0,038)$ \\
\hline
\end{tabular}

Fonte: Estimativas dos autores a partir de dados do BNB e da RAIS.

Obs: Desvio padrão entre parênteses, obtido por bootstrap para as estimativas de propensity score.

Nota: “*” indica significância estatística a 5\%. Foram utilizadas 211 firmas beneficiadas e 1234 firmas não-beneficiadas. Nas estimativas de Propensity Score com kernel foi utilizado o kernel de Epanechnikov. ${ }^{18}$

No que diz respeito às estimativas sem controle algum para diferenças entre as firmas dos dois grupos, as evidências apontam para um impacto positivo do programa sobre a taxa de crescimento do emprego: em média, diferença de 55,7 pontos percentuais na taxa de crescimento do emprego para as firmas beneficiadas em relação à situação de beneficiada. Não há, contudo, evidências estatisticamente significantes favoráveis para o impacto do FNE sobre taxa de variação do salário médio pago pelas firmas.

Apesar de indicarem um efeito ainda maior do FNE sobre a taxa de crescimento do número de empregados das firmas beneficiadas, as duas estimativas de Propensity Score apontam para o mesmo padrão obtido no estimativa "Sem Controle", ou seja, em média, as firmas beneficiadas apresentam um diferencial favorável entre 61,2 e 65,1 pontos percentuais quando se comparam as taxas de variação do número de empregados entre situações de beneficiadas e não-beneficiadas com financiamento do FNE.

\subsubsection{Impacto do FNE nas Firmas Beneficiadas: Estimativas para Micro e Pequenas} Firmas

Em consonância com o foco inicial do programa de financiamento, as firmas com menos de 50 empregados (micro e pequenas firmas) representaram em torno de $86 \%$

18 Para todas as estimativas do trabalho, Tabelas 2 e 3 (FNE), Tabelas 5 e 6, (FNO) e Tabelas 8 e 9 (FCO), não há diferenças substantivas entre os resultados obtidos com a utilização do kernel de Epanechnikov e aqueles gerados a partir de um kernel gaussinano. Por este motivo e pelo mesmo apresentar o menor erro quadrado médio integrado (mean integrated squared error) entre os diferentes kernels (SILVERMAN, 1986), optou-se pelo kernel de Epanechnikov. 
do total da firmas beneficiadas pelo FNE em 2000. A Tabela 3 apresenta as estimativas do impacto dos financiamentos do FNE sobre esse conjunto de firmas, a partir das mesmas variáveis consideradas acima, ou seja, a taxa de variação do número de empregados e a taxa de variação do salário médio pago pelas firmas.

TABELA 3 - IMPACTO DO FNE: DIFERENÇAS ENTRE TAXAS DE VARIAÇÃO DO EMPREGO E DO SALÁRIO MÉDIO NO PERÍODO 20002003. MICRO E PEQUENAS FIR MAS

\begin{tabular}{lcc}
\hline & Taxa de variação Emprego & Taxa de variação Salário Médio \\
\hline \multirow{2}{*}{ Sem Controle } & $0,627^{\star}$ & 0,034 \\
& $(0,239)$ & $(0,029)$ \\
Propensity Score - Estratos & $0,529^{\star}$ & 0,031 \\
& $(0,278)$ & $(0,037)$ \\
Propensity Score - Kernel & $0,640^{\star}$ & 0,030 \\
& $(0,279)$ & $(0,035)$ \\
\hline
\end{tabular}

Fonte: Estimativas dos autores a partir de dados do BNB e da RAIS.

Obs: Desvio padrão entre parênteses, obtido por bootstrap para as estimativas de propensity score.

Nota:“*” indica significância estatística a 5\%. Foram utilizadas 182 firmas beneficiadas e 1068 firmas não-beneficiadas. Mesma especificação do probit para amostra total, exceto pela ausência das categorias médias e grandes firmas. Nas estimativas de Propensity Score com kernel foi utilizado o kernel de Epanechnikov; já as estimativas obtidas a partir de estratos foram obtidas a partir de oito estratos.

De forma geral, as evidências obtidas indicam que os resultados já apontados para o total da amostra refletem as estimativas obtidas para o universo de micro e pequenas firmas, ou seja, nas pequenas e microfirmas, as estimativas do impacto do programa indicam um diferencial positivo entre 52,9 e 64 pontos percentuais para taxa de variação do número de empregados entre as situações de beneficiadas e nãobeneficiadas pelo FNE. De maneira similar ao encontrado para o total da amostra, também não foi obtido nenhum impacto estatisticamente significante sobre a taxa de variação do salário médio pago pelas firmas entre as duas situações (beneficiadas e não-beneficiadas).

\subsection{Fundo Constitucional de Financiamento do Norte - FNO}

Nesta subseção, são apresentadas as estimativas do impacto econômico da aplicação dos recursos do Fundo Constitucional de Financiamento do Norte (FNO) nas firmas beneficiadas e identificadas na RAIS. É importante, mais uma vez, ressaltar que os resultados obtidos referem-se exclusivamente ao universo de firmas beneficiadas com recursos do FNO identificadas na RAIS, o que implica a consideração apenas de firmas do setor formal. 
Quando se considera o período 2000-2003, deve-se chamar a atenção para o fato de que, no ano de 2000, o total de recursos contratados pelo FNO correspondeu aproximadamente a $45 \%$ do total de recursos contratados pelos três fundos constitucionais de financiamento (FCO, FNE e FNO), ficando, pois, acima do contratado pelo FNE. ${ }^{19}$

\subsubsection{Dados e Evidências Iniciais}

As estimativas apresentadas na próxima seção foram obtidas a partir de duas diferentes amostras. Uma primeira amostra é constituída pelas firmas beneficiadas pelo FNO no ano de 2000 da região Norte e que foram identificadas na RAIS desse mesmo ano. Em 2000, no FNO, foi possível identificar 281 firmas, das quais foram excluídas as firmas que também receberam financiamento nos anos de 2001, 2002 e 2003. Assim, a amostra de beneficiadas é constituída por 214 firmas da região Norte do País. A partir do universo de firmas presentes na região Norte, na RAIS, em 2000, e que não receberam financiamento do FNO em nenhum dos anos do período analisado, uma outra amostra de 1.230 firmas (não-beneficiadas ${ }^{20}$ ) foi considerada para o grupo de comparação ou controle.

A Tabela 4 apresenta valores para o conjunto de variáveis utilizadas nas estimativas que permitem, ao mesmo tempo, caracterizar as firmas beneficiadas identificadas e compará-las com a amostra de firmas escolhidas aleatoriamente na RAIS no ano de 2000 .

No que concerne à escolaridade média dos empregados, há uma importante diferença entre os dois conjuntos de firmas. O conjunto de firmas beneficiadas apresenta relativa maior participação de firmas com escolaridade média de seus empregados aos níveis da $\mathrm{l}^{\mathrm{a}}$ à $8^{\mathrm{a}}$ série incompleta. Por sua vez, a amostra RAIS apresenta relativa maior participação de firmas com escolaridade média de seus empregados em níveis mais elevados: $30,4 \%$ das firmas apresentam a escolaridade média dos seus empregados correspondentes ao $2^{\circ}$ grau completo ou mais.

Contudo, a diferença apontada na escolaridade média dos empregados entre as firmas das duas amostras não se verifica nem na idade média nem no salário médio pago aos empregados. Esse último resultado, em vista das diferenças de escolaridade acima apontadas, não deixa de ser curioso.

19 Evidentemente, o mesmo não pode ser dito a respeito dos recursos do Tesouro Nacional, que obedeceram as normas relativas às participações dos Fundos nos recursos disponibilizados.

20 As características e comparação entre as amostras são descritas a seguir. 
Uma parcela importante da explicação disso reside nas diferenças das distribuições de firmas das amostras de acordo com os setores e quanto ao porte, já que as firmas beneficiadas pelo FNO apresentam-se concentradas no setor industrial, e as firmas da amostra RAIS estão concentradas em sua maioria na categoria de micro e pequenas empresas. Note-se, além disso, retornando ao cotejo por níveis educacionais, que para mais de $40 \%$ das firmas nas duas amostras não há diferenças estatisticamente significantes entre as escolaridades médias de seus empregados.

\section{TABELA 4 - FIRMAS BENEFICIADAS PELO FNO E FIRMAS NÃO-BENEFI- CIADAS DA RAIS - 2000}

\begin{tabular}{|c|c|c|}
\hline Variável & FNO formal & RAIS \\
\hline \multicolumn{3}{|l|}{ Grau médio de instrução(\%) } \\
\hline Analfabeto ou da $1^{a}$ à $4^{\mathrm{a}}$ série incompleta & 7,5 & 5,1 \\
\hline $1^{\mathrm{a}}$ até $4^{\mathrm{a}}$ série completa* & 15,5 & 7,8 \\
\hline $5^{\mathrm{a}}$ até $8^{\mathrm{a}}$ série incompleta* & 19,0 & 13,0 \\
\hline $8^{\mathrm{a}}$ série completa & 24,1 & 22,5 \\
\hline 2ºgrau incompleto & 26,4 & 21,2 \\
\hline 2ㅇarau completo ou mais* & 7,5 & 30,4 \\
\hline Idade média dos empregados (anos) & 30,8 & 31,2 \\
\hline \multicolumn{3}{|l|}{ Número de empregados (\%) } \\
\hline Micro e Pequeno porte (até 49 empregados) ${ }^{*}$ & 81,6 & 93,9 \\
\hline Médio e Grande porte (mais de 49 empregados) ${ }^{*}$ & 18,4 & 6,1 \\
\hline Salário médio em SM & 2,02 & 2,35 \\
\hline \multicolumn{3}{|l|}{ Grupo CNAE (\%) } \\
\hline Agropecuária & 12,1 & 9,2 \\
\hline Indústria* & 66,1 & 14,0 \\
\hline Comércio* & 18,4 & 45,1 \\
\hline Serviços* & 3,4 & 31,6 \\
\hline \multicolumn{3}{|l|}{ Estados do Norte (\%) } \\
\hline Rondônia* & 12,1 & 18,9 \\
\hline Acre & 4,0 & 4,8 \\
\hline Amazonas* & 8,6 & 16,0 \\
\hline Roraima* & 0,0 & 2,5 \\
\hline Pará* & 48,3 & 39,1 \\
\hline Amapá* & 1,2 & 4,1 \\
\hline Tocantins* & 25,9 & 14,6 \\
\hline
\end{tabular}

Fonte: Estimativas dos autores a partir de dados da RAIS e do Banco da Amazônia.

Nota: "*"indica significância estatística a 5\% para os testes de diferenças entre médias e entre proporções entre os dois grupos, o que implica rejeição das correspondentes hipóteses nulas de que as médias ou proporções são iguais. 
Por sua vez, há importantes diferenças entre os dois conjuntos de firmas no que diz respeito ao porte e à presença entre os setores. Mais especificamente, mais de $90 \%$ das firmas da RAIS correspondem a pequenas ou microfirmas, percentual acima da amostra de firmas beneficiadas pelo FNO. As diferenças são ainda mais acentuadas quando se considera o corte setorial: enquanto mais de $66 \%$ das firmas beneficiadas pelo FNO pertenciam ao setor industrial, apenas $14 \%$ das firmas da RAIS eram classificadas nessa categoria. Na verdade, mais de 75\% das firmas da RAIS pertenciam aos setores de serviços e ao comércio.

Por fim, o cotejo entre as distribuições das duas amostras de firmas segundo os Estados da região aponta para sobrerrepresentação dos Estados do Pará e Tocantins entre as firmas beneficiadas pelo FNO: em torno de $74 \%$ das firmas beneficiadas pertenciam a esses dois Estados, embora as firmas desses Estados representassem apenas cerca de $54 \%$ das firmas da amostra da RAIS. Nos demais estados, apenas o Acre apresentava uma representação de acordo com seu peso na amostra de firmas da RAIS.

A partir das estimativas dos coeficientes do modelo probit, para cada firma das duas amostras foram obtidas estimativas da probabilidade de ser beneficiada pelo FNO. Essas estimativas foram utilizadas para obter as estimativas de propensity score do FNO. Para se ter uma idéia inicial das probabilidades estimadas, a Figura 3, a partir dos correspondentes histogramas, apresenta as distribuições dessas probabilidades estimadas para os dois conjuntos de firmas, não-beneficiadas (0) e beneficiadas (1), respectivamente.

Os dois histogramas apresentados na Figura 3 mostram distintas distribuições para os dois grupos de firmas quanto à probabilidade de serem beneficiadas com recursos do FNO. De fato, enquanto a maioria das firmas RAIS apresenta probabilidades de até $20 \%$ de serem beneficiadas com recursos do programa, para as firmas beneficiadas, a maioria das firmas apresenta probabilidades acima desse percentual. Essas diferenças refletem o foco específico do programa nas pequenas firmas e nas firmas do setor industrial e, ao mesmo tempo, apontam para o risco potencial, quando da obtenção de estimativas do impacto do programa, de comparações generalizadas que não considerem os diferentes níveis de probabilidades de participação do programa. 
FIGURA 3 - DISTRIBUIÇÕES DAS PROBABILIDADES DE PARTICIPAÇÃO ESTIMADAS

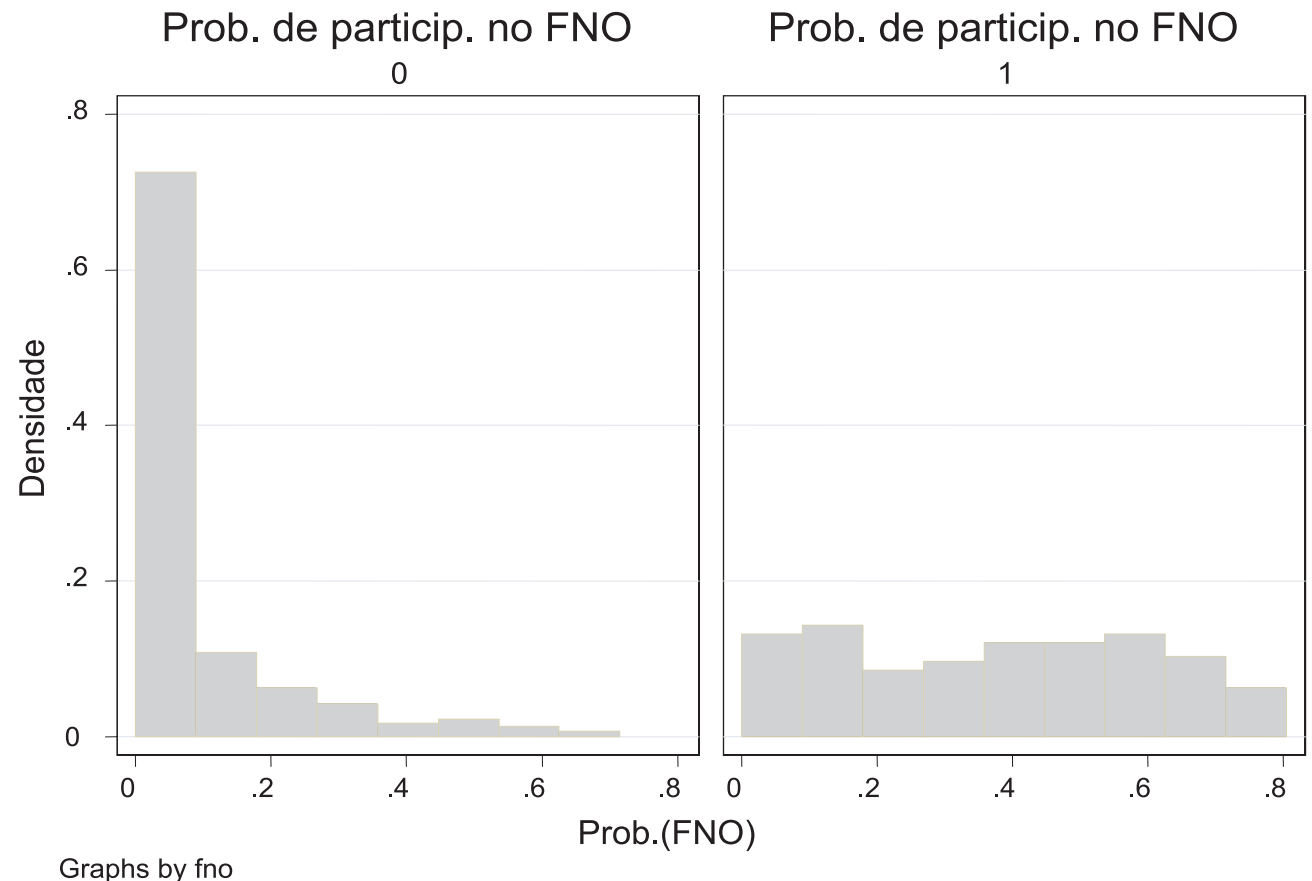

Fonte: Elaboração dos autores.

\subsubsection{Impacto do FNO nas Firmas Beneficiadas: Estimativas Gerais}

Nesta subseção, são apresentadas as estimativas gerais do impacto da aplicação dos recursos do FNO nas firmas beneficiadas, ou seja, os resultados são obtidos considerando toda a amostra de firmas beneficiadas pelo FNO presente na RAIS nos anos de 2000 e 2003. É válido ressaltar que as variáveis focadas correspondem à taxa de variação do número de empregados e a taxa de variação do salário médio das firmas beneficiadas.

No caso da estimação a partir de estratos, foi possível obter sete estratos, nos quais tanto as estimativas de probabilidade como as demais variáveis encontram-se balanceadas entre os dois conjuntos de firmas. 


\section{FIGURA 4 - DISTRIBUIÇÃO DAS FIRMAS ENTRE OS ESTRATOS}

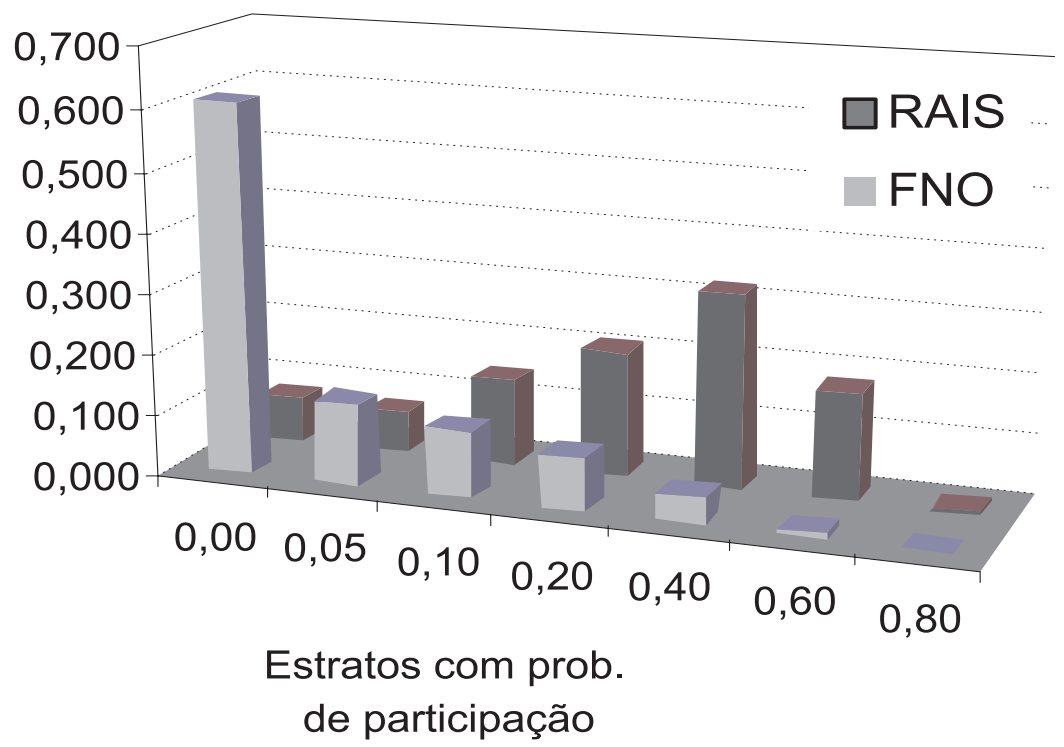

Fonte: Elaboração dos autores.

Para uma rápida percepção da distribuição das firmas entre os sete estratos, a Figura 4 apresenta as distribuições das firmas beneficiadas (FNO) e da RAIS entre estes estratos. Observe que grande parte das firmas RAIS encontra-se no primeiro estrato (entre 0,0 e 0,05 ) e a maior parte das firmas beneficiadas encontra-se nos estratos acima de 0,2 para probabilidade de participação.

Nas estimativas apresentadas a seguir, o estimador de Propensity Score considera apenas comparações entre firmas dentro de cada estrato. Essas estimativas, em conjunto com estimativas obtidas sem nenhum controle quanto à probabilidade de participação e com estimativas que fazem uso de um kernel, são apresentadas na Tabela 5.

De acordo com as estimativas da Tabela 5, todas as estimativas das diferenças de desempenho das firmas sob a condição de beneficiadas e sob a condição de nãobeneficiadas pelo FNO não apontam para um impacto favorável do programa. 
TABELA 5 - IMPACTO DO FNO: DIFERENÇAS ENTRE TAXAS DE VARIAÇÃO DO EMPREGO E DO SALÁRIO MÉDIO NO PERÍODO 20002003

\begin{tabular}{lcc}
\hline & Tx. de variação Emprego & Tx. de variação Salário Médio \\
\hline Sem Controle & 0,023 & 0,014 \\
& $(0,129)$ & $(0,032)$ \\
Propensity Score - Estratos & $-0,102$ & $-0,019$ \\
& $(0,245)$ & $(0,037)$ \\
Propensity Score - Kernel & 0,011 & 0,002 \\
& $(0,249)$ & $(0,038)$ \\
\hline
\end{tabular}

Fonte: Estimativas dos autores a partir de dados do Banco da Amazônia e da RAIS.

Obs: Desvio padrão entre parênteses, obtido por bootstrap para as estimativas de propensity score.

Nota:“*” indica significância estatística a 5\%. Foram utilizadas 214 firmas beneficiadas e 1230 firmas nãobeneficiadas. Nas estimativas de Propensity Score com kernel foi utilizado o kernel de Epanechnikov.

Em outras palavras, com nenhum dos estimadores utilizados foi possível obter impacto positivo do programa sobre a taxa de variação do número de empregados ou sobre a taxa de variação do salário médio pago pelas firmas beneficiadas.

\subsubsection{Impacto do FNO nas Firmas Beneficiadas: Estimativas para Micro e Pequenas Firmas}

Em 2000, cerca de $81 \%$ das firmas beneficiadas pelo FNO tinham menos de 50 empregados na sua força de trabalho. Observe que, pela não significância estatística de todos os valores estimados apresentados na Tabela 6 , não se obtêm, também, para micro e pequenas firmas, resultados favoráveis ao programa de financiamentos do FNO.

Ou seja, tanto para a taxa de variação do número de empregos quanto para a taxa de variação do salário médio pago pelas firmas, em nenhum dos casos foi possível rejeitar as hipóteses de que o desempenho das firmas beneficiadas é igual àquele que apresentariam caso não tivessem recebido os recursos do FNO. 
TABELA 6 - IMPACTO DO FNO: DIFERENÇAS ENTRE TAXAS DE VARIAÇAO DO EMPREGO E DO SALÁRIO MÉDIO NO PERÍODO 20002003. MICRO E PEQUENAS FIRMAS

\begin{tabular}{lcc}
\hline & Tx. de variação Emprego & Tx. de variação Salário Médio \\
\hline \multirow{2}{*}{ Sem Controle } & 0,122 & 0,038 \\
& $(0,152)$ & $(0,037)$ \\
Propensity Score - Estratos & 0,162 & $-0,007$ \\
& $(0,222)$ & $(0,042)$ \\
Propensity Score - Kernel & 0,132 & $-0,002$ \\
& $(0,228)$ & $(0,035)$ \\
\hline
\end{tabular}

Fonte: Estimativas dos autores a partir de dados do Banco da Amazônia e da RAIS.

Obs: Desvio padrão entre parênteses, obtido por bootstrap para as estimativas de propensity score.

Nota: “*” indica significância estatística a 5\%. Foram utilizadas 174 firmas beneficiadas e 1154 firmas nãobeneficiadas. Nas estimativas de Propensity Score com kernel foi utilizado o kernel de Epanechnikov; já as estimativas obtidas a partir de estratos foram obtidas a partir de sete estratos.

\subsection{Fundo Constitucional de Financiamento do Centro-Oeste - FCO}

Em relação ao período de avaliação, 2000-2003, são obtidas as estimativas de impacto para as duas variáveis supramencionadas. Além disso, é válido destacar que a avaliação restringe-se às empresas tomadoras dos recursos do FCO identificadas na RAIS de 2000. Ademais, de maneira similar ao FNE e ao FNO, em virtude de maior prioridade, além de evidências para todo o conjunto de firmas beneficiadas identificadas na RAIS foi obtido um conjunto adicional de evidências para o subgrupo de micro e pequenas firmas.

\subsubsection{Dados e Evidências Iniciais}

As estimativas foram obtidas a partir de duas diferentes amostras. Uma primeira amostra é constituída pelas firmas beneficiadas pelo FCO no ano de 2000 da região Centro-Oeste e que foram identificadas na RAIS nesse mesmo ano. Das 110 firmas beneficiadas pelo FCO em 2000, foi possível identificar 86 firmas, das quais foram excluídas as firmas que também receberam financiamento nos anos de 2001, 2002 e 2003. Assim, a amostra de beneficiadas é constituída por 75 firmas da região Centro-Oeste do País. Do universo de firmas da região Centro-Oeste presentes na RAIS em 2000 e que não receberam financiamento do FCO em nenhum ano, uma outra amostra de 1.204 firmas não-beneficiadas foi considerada para o grupo de comparação ou controle. 
Uma descrição das variáveis consideradas nas estimativas e uma comparação das características das duas amostras utilizadas são possíveis a partir dos números presentes na Tabela 7. O primeiro conjunto de evidências da Tabela 7 indica que, no que diz respeito ao nível de escolaridade dos empregados, há diferenças entre as firmas beneficiadas e não-beneficiadas. De forma semelhante às firmas beneficiadas pelo FNE, a distribuição das firmas beneficiadas pelo FCO aponta para maior presença de firmas com empregados no grupo de escolaridade média (64\% das firmas situamse no grupo de escolaridade dos empregados com $5^{\text {a }}$ série até $8^{a}$ série completa). Por sua vez, as firmas não-beneficiadas encontram-se mais bem distribuídas entre os diferentes grupos de escolaridade média dos empregados; todavia, vale destacar, também estão mais presentes no grupo de mais elevada escolaridade.

No que concerne à idade média dos empregados, não há diferenças importantes entre os dois conjuntos de firmas, não obstante essas aparecem quando se considera o porte das firmas. Especificamente, nota-se que tanto as firmas beneficiadas como as não-beneficiadas pelo FCO são, em sua maior parte, classificadas como micro ou pequenas firmas, embora o percentual das últimas sob essa classificação seja maior (percentuais, respectivamente, $82,7 \%$ e $90,1 \%$ ).

Como no caso do FNE, também os valores da Tabela 7 indicam que, em média, as firmas beneficiadas pagavam um salário menor que as firmas não-beneficiadas da RAIS. Precisamente, as firmas do setor formal da região Centro-Oeste pagavam, em 2000, um salário médio $10 \%$ maior que aquele pago pelas firmas beneficiadas pelo FCO, resultado novamente consistente com a maior presença das firmas nãobeneficiadas no grupo de empregados com maior escolaridade, o que também pode indicar situação economicamente mais frágil (mais baixa produtividade) das firmas beneficiadas.

Entretanto, a diferença mais marcante entre os dois grupos de firmas diz respeito às respectivas distribuiçôes de acordo com os grandes setores econômicos, isto é, em 2000 , quase $70 \%$ das firmas beneficiadas pelo FCO pertenciam ao setor industrial, enquanto quase $70 \%$ das firmas não-beneficiadas da RAIS eram do setor do comércio e dos serviços. De fato, em 2000 houve um claro foco na aplicação de recursos do FCO no setor industrial.

Diferentemente do que foi encontrado na aplicação dos recursos do FNE, a distribuição das firmas beneficiadas pelo FCO entre os Estados da região Centro-Oeste reflete a própria distribuição espacial da atividade econômica na região, ao menos aquela apontada a partir das firmas não-beneficiadas da RAIS. Ou seja, os valores da tabela indicam que nenhum Estado foi privilegiado quanto à distribuição do número de firmas beneficiadas. 
TABELA 7 - PERFIS DAS FIRMAS BENEFICIADAS PELO FCO E DAS FIRMAS NATO-BENEFICIADAS DA RAIS - 2000

\begin{tabular}{|c|c|c|}
\hline Variável & FCO formal & RAIS \\
\hline \multicolumn{3}{|l|}{ Grau médio de instrução(\%) } \\
\hline Analfabeto ou da $1^{\mathrm{a}}$ à $4^{\mathrm{a}}$ série incompleta* & 0,0 & 12,2 \\
\hline $1^{\mathrm{a}} \quad$ até $4^{\mathrm{a}}$ série $\quad$ completa $^{*}$ & 4,0 & 11,2 \\
\hline até $8^{\mathrm{a}}$ série incompleta & 26,7 & 20,0 \\
\hline $8^{\mathrm{a}}$ série completa* & 37,3 & 17,2 \\
\hline 2orau incompleto & 24,0 & 14,2 \\
\hline 2ํgrau completo ou mais ${ }^{*}$ & 8,0 & 25,1 \\
\hline Idade média dos empregados (anos) & 32,6 & 31,9 \\
\hline \multicolumn{3}{|l|}{ Número de empregados (\%) } \\
\hline Micro e Pequeno porte (até 49 empregados) ${ }^{\star}$ & 82,7 & 90,1 \\
\hline Médio e Grande porte (mais de 49 empregados) $)^{\star}$ & 17,3 & 9,9 \\
\hline Salário médio em SM* & 2,50 & 2,75 \\
\hline \multicolumn{3}{|l|}{ Grupo CNAE (\%) } \\
\hline Agropecuária* & 1,3 & 16,8 \\
\hline Indústria* & 69,3 & 14,6 \\
\hline Comércio & 25,3 & 35,5 \\
\hline Serviços* & 4,0 & 32,1 \\
\hline \multicolumn{3}{|l|}{ Unidades da Federação do Centro-Oeste (\%) } \\
\hline Mato Grosso do Sul & 22,7 & 21,1 \\
\hline Mato Grosso & 12,0 & 21,0 \\
\hline Goiás & 48,0 & 38,0 \\
\hline Distrito Federal & 17,3 & 20,0 \\
\hline
\end{tabular}

Fonte: Estimativas dos autores a partir de dados da RAIS e do BB.

Nota: “* " indica significância estatística a 5\% para os testes de diferenças entre médias e entre proporções entre os dois grupos, o que implica rejeição das correspondentes hipóteses nulas de que as médias ou proporçôes são iguais.

Para ilustrar as estimativas de propensity score para os conjuntos de firmas beneficiadas e não-beneficiadas, a Figura 5 apresenta, a partir dos respectivos histogramas, as distribuições dessas estimativas para os dois conjuntos de firmas.

Os dois histogramas refletem distribuições distintas. Mais especificamente, por exemplo, enquanto em torno de $93 \%$ das firmas da RAIS (não-beneficiadas) apresentam menos de $20 \%$ de probabilidade estimada de participação, para as firmas beneficiadas menos de $34 \%$ não chegam a este percentual. 


\section{FIGURA 5 - DISTRIBUIÇÕES DAS PROBABILIDADES DE PARTICIPAÇÃO ESTIMADAS}

Prob. de particip. no FCO

0

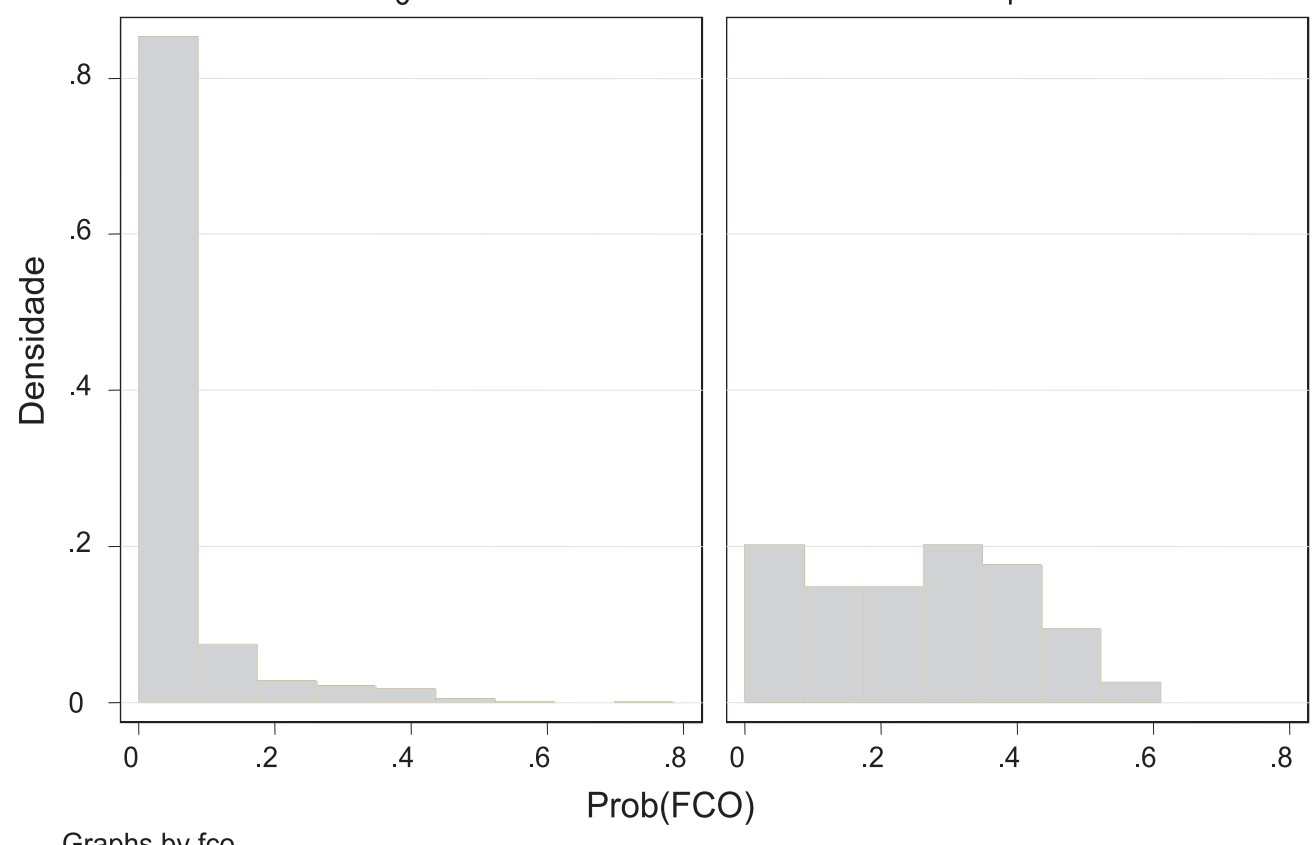

Graphs by fco

Prob. de particip. no FCO

1

Fonte: Elaboração dos autores.

Essas diferenças refletem o foco específico do programa nas firmas do setor industrial e, ao mesmo tempo, apontam para o risco potencial, quando da obtenção de estimativas do impacto do programa, de comparações generalizadas que não considerem os diferentes níveis de probabilidades de participação do programa.

\subsubsection{Impacto do FCO nas Firmas Beneficiadas: Estimativas Gerais}

No caso da estimação a partir de estratos, foi possível obter seis estratos, nos quais tanto as estimativas de probabilidade como as demais variáveis encontram-se balanceadas entre os dois conjuntos de firmas. Para uma visualização da distribuição das firmas entre os seis estratos, a Figura 6 apresenta as distribuiçóes das firmas beneficiadas (FCO) e da RAIS entre esses estratos.

Observe que grande parte das firmas RAIS (cerca de 75\%) encontra-se no primeiro estrato (entre 0,0 e 0,05 ) e a maior parte das firmas beneficiadas encontra-se nos estratos acima de 0,2 para probabilidade de participação. 
FIGURA 6 - DISTRIBUIÇÃO DAS FIRMAS ENTRE OS ESTRATOS

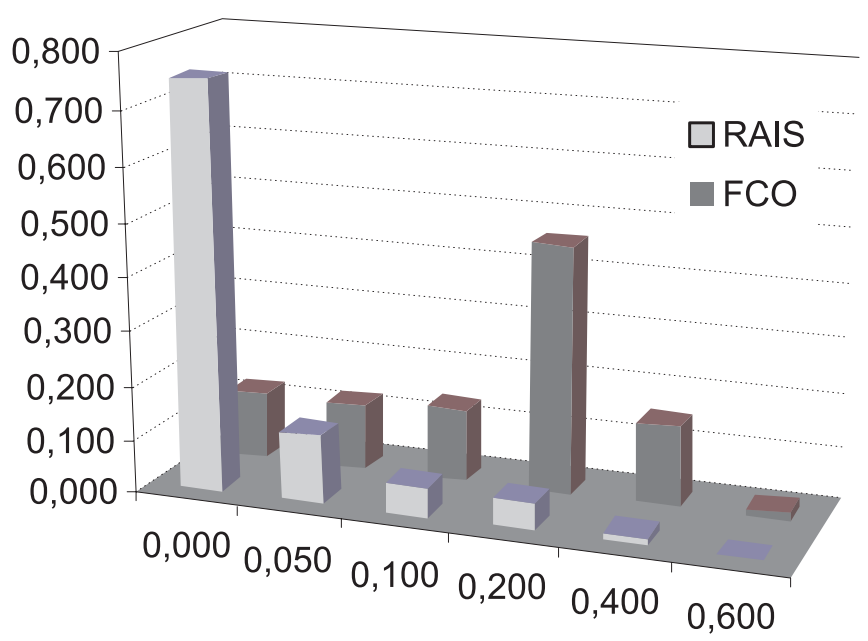

Estratos com prob. de participação

Fonte: Elaboração dos autores.

Nas estimativas apresentadas na Tabela 8, o estimador de Propensity Score por estratos considera apenas comparações entre firmas dentro de cada estrato. Essas estimativas, em conjunto com estimativas obtidas sem nenhum controle em relação à probabilidade de participação e com estimativas que fazem uso de um kernel, são apresentadas na Tabela 8.

De acordo com a referida tabela, em nenhuma das estimativas das diferenças de desempenho das firmas entre a condição de beneficiadas e a condição de não-beneficiadas pelo FCO, obteve-se impacto favorável do programa. Assim, seja utilizando estimador de Propensity Score, seja estimando-se o impacto sem controle, não foi possível obter impacto positivo do programa sobre a taxa de variação do número de empregados ou sobre a taxa de variação do salário médio pago pelas firmas beneficiadas. 
TABELA 8 - IMPACTO DO FCO: DIFERENÇAS ENTRE TAXAS DE VARIAÇAO DO EMPREGO E DO SALÁRIO MÉDIO NO PERÍODO 20002003

\begin{tabular}{lcc}
\hline & Tx. de variação Emprego & Tx. de variação Salário Médio \\
\hline Diferenças das Médias & 0,820 & 0,045 \\
& $(0,666)$ & $(0,051)$ \\
Propensity Score - Estratos & 0,987 & 0,032 \\
& $(0,664)$ & $(0,048)$ \\
Propensity Score - Kernel & 0,978 & 0,032 \\
& $(0,698)$ & $(0,058)$ \\
\hline
\end{tabular}

Fonte: Estimativas dos autores a partir de dados do Banco do Brasil e da RAIS.

Obs: Desvio padrão entre parênteses, obtido por bootstrap para as estimativas de propensity score.

Nota: “*”indica significância estatística a 5\%. Foram utilizadas 74 firmas beneficiadas e 1204 firmas nãobeneficiadas. Nas estimativas de Propensity Score com kernel foi utilizado o kernel de Epanechnikov.

Dessa forma, para o período 2000-2003, as evidências obtidas quanto ao impacto dos financiamentos do FCO, ao menos para as duas variáveis consideradas no que concerne às firmas do setor formal, indicam que tais financiamentos não implicam melhor desempenho das firmas beneficiadas em relação à condição alternativa de não-beneficiadas.

\subsubsection{Impacto do FCO nas Firmas Beneficiadas: Estimativas para Micro e Pequenas Firmas}

Em 2000, em torno de 83\% das firmas beneficiadas pelo FCO tinham menos de 50 empregados na sua força de trabalho. Como se pode observar pela não-significância estatística de todos os valores estimados apresentados na Tabela 9, não se obtêm, também, para micro e pequenas firmas, resultados favoráveis ao programa de financiamentos do FCO. Ou seja, tanto para a taxa de variação do número de empregos quanto para a taxa de variação do salário médio pago pelas firmas, em nenhum dos casos foi possível rejeitar as hipóteses de que o desempenho das firmas beneficiadas é igual àquele que apresentariam caso não tivessem recebido os recursos do FCO. 
TABELA 9 - IMPACTO DO FCO: DIFERENÇAS ENTRE TAXAS DE VARIAÇAO DO EMPREGO E DO SALÁRIO MÉDIO NO PERÍODO 20002003. MICROS E PEQUENAS FIRMAS

\begin{tabular}{lcc}
\hline & Tx. de variação Emprego & Tx. de variação Salário Médio \\
\hline Diferenças das Médias & 1,026 & 0,064 \\
& $(0,805)$ & $(0,059)$ \\
Propensity Score - Estratos & 1,165 & 0,059 \\
& $(0,881)$ & $(0,064)$ \\
Propensity Score - Kernel & 1,201 & 0,060 \\
& $(0,837)$ & $(0,069)$ \\
\hline
\end{tabular}

Fonte: Estimativas dos autores a partir de dados do Banco do Brasil e da RAIS.

Obs: Desvio padrão entre parênteses, obtido por bootstrap para as estimativas de propensity score.

Nota:“*” Indica significância estatística a 5\%. Foram utilizadas 61 firmas beneficiadas e 1084 firmas nãobeneficiadas. Nas estimativas de Propensity Score com kernel foi utilizado o kernel de Epanechnikov.

\section{CONCLUSÕES}

O presente artigo objetivou avaliar a aplicação dos recursos do Fundo Constitucional de Financiamento do Nordeste (FNE), do Fundo Constitucional de Financiamento do Norte (FNO) e do Fundo Constitucional de Financiamento do Centro-Oeste (FCO). Destaque-se que as informações apresentadas resultam de um esforço pioneiro na utilização de microdados sobre firmas beneficiadas com esse tipo de financiamento público.

Nessa tarefa de avaliação, em virtude da necessidade de construção de grupos de firmas de controle (não-beneficiadas) e de grupos de firmas beneficiadas com recursos desses fundos, foram utilizadas apenas firmas identificadas na RAIS, o que significa a consideração de apenas firmas do setor formal. Adicionalmente, em função dessa utilização exclusiva da RAIS como fonte de informações sobre as firmas e de forma consistente com os objetivos da aplicação dos recursos do FNE, do FNO e do FCO, somente duas variáveis foram tomadas como referências para avaliar desempenho das firmas: a taxa de variação do número de empregados e a taxa de variação do salário médio pago pelas firmas.

A partir das performances com respeito a essas duas variáveis e de acordo com a condição de beneficiadas e não-beneficiadas, os resultados da avaliação da aplicação dos recursos do FNO e do FCO revelaram semelhanças. 
Em relação ao FNE, o resultado geral a destacar diz respeito ao impacto sobre as duas variáveis consideradas: enquanto para a taxa de variação do salário médio pago pelas firmas não foi possível apontar impacto positivo da aplicação dos recursos, para a taxa de variação do número de empregados os resultados permitem apontar um resultado positivo da aplicação dos recursos desse fundo sobre as firmas beneficiadas.

No que concerne ao FNO e ao FCO, o resultado geral a destacar também diz respeito ao impacto sobre as duas variáveis consideradas: nesse caso, em nenhuma circunstância foi possível apontar impacto positivo da aplicação dos recursos. Em outras palavras, tanto para a taxa de variação do salário médio pago pelas firmas quanto para a taxa de variação do número de empregados, não é possível apontar um resultado positivo da aplicação dos recursos desses fundos sobre as firmas beneficiadas.

Quando estimativas da aplicação dos recursos do FNO e do FCO foram obtidas para o subgrupo específico micro e pequenas firmas, as semelhanças entre os resultados das duas avaliações continuaram robustas, o que sugere consistência com respeito aos resultados obtidos. Mais especificamente, de forma similar ao resultado encontrado quando se considera toda a amostra, na avaliação da aplicação dos recursos do FNO ou do $\mathrm{FCO}$, no que diz respeito às pequenas e microfirmas, não é possível apontar impacto positivo sobre a taxa de variação do número de empregados nem sobre a taxa de variação do salário médio pago pelas firmas beneficiadas.

No caso do FNE, ao se considerar o subgrupo específico micro e pequenas firmas, é possível apontar um impacto positivo (em relação a firmas não-beneficiadas) na taxa de variação do número de empregados de magnitude similar ao apontado quando todo o universo de firmas é considerado.

É possível que o melhor desempenho do FNE seja explicado pela melhor gerência na aplicação dos recursos e/ou pelo menor acesso a financiamentos alternativos das firmas não-beneficiadas . Contudo, dado o conjunto de informações disponível, não se consegue ser decisivo a respeito. De fato, já que não foi possível levantar informações a respeito das assessorias técnicas e administrativas dos bancos nem dos valores dos empréstimos concedidos para as firmas de acordo com o seu porte, não é possível tecer comentários detalhados sobre uma dessas duas possibilidades.

De qualquer forma, é válido mencionar que os resultados obtidos são consistentes com o menor acesso relativo das firmas presentes no espaço geográfico abrangido pelo FNE a canais alternativos de financiamento (sistema financeiro, BNDES, recursos próprios etc.), o que naturalmente tende a aumentar a importância dos recursos do FNE para essas firmas. De fato, isso significaria que as firmas não-beneficiadas 
com os recursos nas regiões Norte e Centro-Oeste estariam em situações mais favoráveis que as correspondentes da região Nordeste, a região mais pobre, o que favoreceria a obtenção de resultados menos favoráveis da aplicação dos recursos do FNO e FCO, respectivamente. Note-se, em particular, que isso é muito importante para a metodologia utilizada, já que, em geral, é extremamente difícil garantir que as firmas do grupo de controle não tenham acesso a mecanismos alternativos externos de financiamento.

Nesse caso, os recursos públicos desses fundos constitucionais estariam sendo bem alocados na região Nordeste e não nas outras duas. Entretanto, dado o conjunto de informações disponível neste estágio da pesquisa, não se pode ser decisivo a respeito, razão pela qual novas investigações precisam ser feitas, tais como pesquisa de campo para obtenção de dados primários.

Deve-se reconhecer que, como todos os demais trabalhos que empregam a metodologia utilizada, o presente estudo é passível de ponderações e críticas uma vez que não necessariamente os fatores observáveis das firmas estudadas são suficientes para garantir que as firmas tomadoras (grupo de tratamento) sejam similares às firmas não-tomadoras, no grupo de controle construído. Isso poderia então estar causando algum viés nas estimativas. Ora, não se pode esquecer que os fundos constitucionais de financiamento são alocados a firmas que se candidataram aos empréstimos e tiveram esses empréstimos aprovados. Dessa forma, é de se esperar que, caso exista alguma diferença não observada no dinamismo e na competitividade intrínseca das firmas tomadoras, em relação ao grupo de controle, esse viés seria em favor das firmas tomadoras. Assumindo-se que os bancos de fomento (BNB, BASA e Banco do Brasil) aprovam empréstimos a empresas com maior rating de crédito, em princípio, o grupo de beneficiadas seria mais dinâmico do que o grupo de controle - ou seja, caso houvesse algum viés nas estimativas dos impactos dos fundos constitucionais de financiamento, esse viés seria em favor do efeito positivo dos fundos constitucionais - o que, conforme discutido na quarta seção, quando houve, no caso do FNE, foi muito baixo.

Por fim, destaque-se a implicação dos resultados deste estudo para a política de desenvolvimento regional brasileira. É válido ressaltar que um dos objetivos dos fundos constitucionais de financiamento é reduzir as desigualdades regionais por meio, entre outros fatores, da geração de empregos e de renda. O mecanismo para essa geração de emprego e renda da política regional ora considerada é justamente por meio da geração de empregos nas empresas beneficiadas com empréstimos e, se possível, aumento dos salários, devido a aumento da qualificação da mão-de-obra empregada nessas tomadoras. Assim, os casos em que não se observam efeitos relevantes dos fundos constitucionais de financiamento sobre a geração de emprego 
e aumento de renda nas empresas que tomaram os empréstimos indicam que essa política tem sido completamente ineficaz em relação aos agregados macroeconômicos geração de emprego e aumento da renda das regiôes favorecidas.

\section{REFERENCIAS}

ANGRIST, E.J.; KRUEGER, A.B. Empirical strategies in labor economics. In: ASHENFELTER, O.; CARD, D., Handbook of Labor Economics , v. 3, 1999.

BECKER, S.O.; ICHINO, A. Estimation of average treatment effects based on propensity score. The Stata Journal, 2(4), p. 358-377, 2002.

BRASIL. Ministério do Planejamento Orçamento e Gestão, Secretaria de Orçamento Federal (SOF). Vinculações de receitas dos orçamentos fiscal e da seguridade social e o poder discricionário da alocação dos recursos do governo federal, v. 1, n. 1, 2003.

DEHEJIA, R.H.; WAHBA, S. Propensity score-matching methods for non-experimental causal studies. The Review of Economics and Statistics, 84(1), p. 151-161, Feb. 2002.

FRIENDLANDER, D.; GREENBERG, D.H.; ROBINS, P.K. Evaluating government training programs for economically disadvantaged. Journal of Economic Perspectives, v. XXXV, Dec.1997.

MAGALHÃES, A.M.; SILVEIRA NETO, R.M.; DIAS, F.M.; RANDS, A. A experiência recente do PRONAF em Pernambuco: uma análise por meio de propensity score. Economia Aplicada, v. 10, n. 1, p. 57-74, 2006.

RESENDE, A.C.C.; OLIVEIRA, A.M.H.C. Avaliando resultados de um programa de transferências de renda: o impacto do Bolsa-Família sobre os gastos das famílias brasileiras. Anais do XXXIV Encontro Nacional de Economia. Salvador, dez. 2006.

ROSENBAUM, P. Observational Studies. $2^{\text {nd }}$ ed. New York: Springer, 2002. (Springer series in statistics).

; RUBIN, D. The central role of propensity score in observational studies for causal effects. Biometrika, v. 70, 1983.

SILVEIRA NETO, R.M. Eficácia e viés de seleção em programas de qualificação em trabalhadores em situação economicamente desvantajosa: evidências para o estado de Pernambuco. Revista Econômica do Nordeste, v. 4, n. 1, p. 1-22, 2002.

SILVERMAN, B.W. Density estimation for statistics and data analysis. London: Chapman and Hall, 1986.

WOOLDRIDGE, J. M. Econometric Analysis of Cross Section and Panel Data. Cambridge: MIT press, 2002. 